\title{
EN TORNO A UNA RECONSTRUCCIÓN HISTÓRICA DE LA COMPLEJIDAD: ORGANICISMO, RÉGIMEN DE PODER Y NUEVAS CIENCIAS TECNOLÓGICAS
}

\author{
M. Inés Alonso Brá \\ Universidad de Buenos Aires, Argentina
}

\begin{abstract}
Resumen: El artículo explora, como interrogante metodológico para las ciencias sociales y humanas, el proceso histórico reciente de emergencia de las teorías y del concepto de complejidad. De modo expreso, se sitúa en un espacio de intersección entre los sistemas cognoscitivos propios de la lógica científica y un contexto sociohistórico particular. Así, describe como hipótesis, la emergencia de una episteme operacional que acompaña el surgimiento de las nuevas ciencias tecnológicas (ciberciencias) al amparo de una ideología organicista, en los Estados Unidos de mediados del siglo pasado. Proceso éste que habría permitido una nueva factibilidad de los regímenes de poder al afectar principios de la episteme moderna. Para ello, son presentados algunos presupuestos y discusiones de los estudios sobre ciencia, sociedad y tecnología, y el trabajo de Gregory Bateson como caso que ilustra esta metanarrativa de emergencia propuesta. Finalmente, extrae algunas conclusiones en relación con el interrogante que lo orienta.
\end{abstract}

Palabras clave: complejidad, organicismo, régimen de saber-poder, Gregory Bateson, episteme operacional, ciberciencias

\section{Around a historical reconstruction of complexity: organicism, power system and new technological sciences}

\begin{abstract}
The paper explores, including methodological question for the social sciences, the historical process of emergence of new theories and the concept of complexity. Explicitly, is situated in an area of intersection between cognitive systems themselves of scientific logic and particular socio-historical context. It describes the hypothesis, the emergence of an operational episteme that accompanies the emergence of new technological sciences under organicist ideology in the United States in mid-century. A process that would have allowed a new feasibility of the regimes of power to affect the early modern episteme. To do this, budgets are presented some studies on science, society and technology, and the work of Gregory Bateson as a case that illustrates this proposed emergency metanarrative.

Finally, draws some conclusions about the question guides it.
\end{abstract}

Keywords: complexity, organicism, knowledge-power regime, Gregory Bateson, operational episteme 


\section{Introducción}

El trabajo puede comprenderse en relación con el vasto interrogante por cómo comprender la emergencia histórica de los estudios en complejidad desde las ciencias sociales y, en concordancia, en la interpelación acerca de cuáles serían las vías para explorarlo. Para ello, presupongo que estos estudios son usualmente investidos por una visión hegemónica de la tecnociencia, comprendida ésta como proceso de crecimiento exponencial de la ciencia moderna y de sus principios a través de sus aplicaciones tecnosociales; deriva donde la tecnología desplaza la hegemonía de la ciencia básica en la producción de saber. Una perspectiva que, en clave de historia de la ciencia, se presenta externa a la lógica de producción de la ciencia y por ello no podría dar cuenta de la aparición del concepto científico de "complejidad". En otro linaje, se encontrarían aquellas orientaciones de matiz positivista que restringen el proceso histórico a las exigencias internas y excluyentes de una identidad propiamente científica, o de otra forma, a la lógica inherente a determinado sistema cognoscitivo. Plantearé, alternativamente, la posibilidad de creación de las teorías y del concepto de complejidad en un espacio de intersección entre un determinado sistema cognoscitivo y particulares condiciones socio-históricas.

Con ese objeto, describo algunas perspectivas de indagación en torno a la relación entre la ciencia, la tecnología y la sociedad, para desde estas propuestas de estudio trazar una vía exploratoria sobre la emergencia particular de las ciberciencias en la sociedad estadounidense de mediados de siglo pasado. Una emergencia enlazada a cuestiones que, aunque científicamente sobreentendidas, entran en escisión con la episteme moderna al amparo de una ideología organicista que hace posible una nueva factibilidad de los regímenes de poder. Luego, me centro en el análisis del trabajo de Gregory Bateson como caso que ilustra, para el campo de las ciencias sociales, la metanarrativa de emergencia propuesta. Y, finalmente, extraigo algunas conclusiones con relación al interrogante general que guía el trabajo.

\section{Un recorrido: de la ciencia a la tecnociencia}

Ciencia es la designación bajo la cual el occidente grecocristiano se ha convertido en la civilización mundial imperante. Pero ello supone que la misma "ciencia" ha recorrido una historia y que sólo en el curso de esa historia ha llegado a ser "la ciencia" [H-G. Gadamer]

En palabras de Gadamer podríamos decir que sólo en el curso de esa múltiple y aleatoria historia "la ciencia" ha llegado a ser "la tecnociencia". Si hoy para Derrida la racionalidad teletecnocientífica no puede sino dar por supuesta la fiabilidad (un acto de "fe" elemental e irreductible) que vincula el saber de la comunidad científica con el hacer y a la ciencia con la técnica; es porque este acto de "fe" es el que sostendría a la racionalidad esencialmente económica y 
capitalística de lo teletecnocientífico ${ }^{1}$. Como contrapartida en nuestra vida cotidiana, Lizcano observa que quien quisiera comprobar por sí mismo la verdad de cualquier enunciado científico, practicando ese otro acto de "fe" elemental propio del espíritu crítico emancipador moderno de la ciencia, se encontrará inmerso en una densa red tejida con argumentos de autoridad, con instrumentos de imposible acceso y con jergas incomprensibles ${ }^{2}$.

Si bien toda pretensión de verdad se libra bajo la autoridad, el anonimato y la hiper especialización de lo tecnocientífico, la ciencia sigue siendo un sistema de creencias que, como otros, da respuestas de un modo que le es propio. Lo que hoy parece sobresaliente es que responde a los por qué a través del cómo con una modalidad particular, la ciencia puede comprenderse desde mediados del siglo XX como un saber operacional. De allí la coetánea crítica de Marcuse sobre los modos de pensamiento científico y social bajo la transformación de la razón tecnológica en razón política, en cuanto a que ya no nos permitiríamos emplear como instrumentos de nuestro pensamiento conceptos que no podamos describir en términos de operaciones ${ }^{3}$.

En esta perspectiva operacional, cualquier explicación aparece como resultado de reformular la experiencia originaria a otros términos. $\mathrm{Si}$ las respuestas científicas son generativas ${ }^{4}$, podríamos sugerir siguiendo a Samaja, que también en otros sistemas de creencias la explicación es la reformulación de la experiencia en términos de los mecanismos que generan el hecho como resultado de su operación. Puede pensarse así que las respuestas míticas son también operacionales, generan el hecho como resultado de su operación a través de mecanismos dramáticos y con sujetos dotados de consciencia. A diferencia, la explicación científica en sentido estricto funcionaría con mecanismos resultantes de las propiedades internas de sistemas formales, los cuales producen el fenómeno una vez que fueron establecidas las premisas. Sería una tautología cuya verdad depende exclusivamente de aquello que hemos puesto en las premisas ${ }^{5}$. Bajo esta visión, la pregunta acerca del ¿por qué? se asimila en un cómo auto-generador, o de otra forma, la explicación

\footnotetext{
${ }^{1}$ Es por ello que Derrida al pensar la relación entre ciencia y religión sostiene que hoy en día, en el denominado "retorno de las religiones", no hay incompatibilidad entre los "fundamentalismos" e "integrismos" y la credibilidad fiduciaria tele-tecno-capitalístico-científica, en todas sus dimensiones mediáticas y mundializantes. (2003) Derrida, Jacques, El siglo y el perdón. Fe y saber. Buenos Aires, Ediciones de La Flor, pp.95-97

2 (2009)Lizcano, Emmánuel, Metáforas que nos piensan. Sobre ciencia, democracia y otras poderosas ficciones. Buenos Aires, Biblos, 2009, p.258

3 (2005) Marcurse, Herbert, El hombre unidimensional, Ariel, Barcelona, pp.42-43 y pp.116-117.

4 En esta visión epistemológica Ver (1987) Maturana, Humberto, Biología del Fenómeno social, Terapia, Año X, N016, Buenos Aires. Ver (1990) Maturana, Humberto, Biología de la cognición y epistemología, Universidad de la Frontera, Chile. Ver (1998) Maturana, Humberto y Varela, Francisco, El árbol del conocimiento, Editorial Universitaria, Chile.

${ }^{5}$ Más precisamente: "La explicación científica se desarrolla en un ir y venir entre la experiencia y la teoría. Es una operación que resulta de ese movimiento de mediación (...) [en el que] se logra mostrar y fundamentar que lo dicho en una descripción puede hacerse corresponder con los términos de una tautología, de modo que los que sucede en el mundo de los hechos es tan obvio como obvia nos parece la tautología; y a la inversa, cuando podemos adjudicar al modelo teórico que hemos construido un modelo real que le corresponde en nuestro campo experienciable" (1994) Samaja, J, Epistemología y Metodología. Elementos para una teoría de la investigación científica, Eudeba, Buenos Aires, pp. 145146. Es así que para este epistemólogo, el proceso de investigación no transcurre en la clásica tensión binaria teoría/empiria, sino en una que la condensa en un tercer componente: el objeto modelo (teoría/objeto modelo/ empiria).
} 
científica es definida como un modelo teórico operativo axiomatizado ${ }^{6}$. Un sentido restrictivo de ciencia si pensamos en las diversas prácticas y tradiciones de investigación de las ciencias sociales y humanas ${ }^{7}$.

De modo paradigmático, los procesos de investigación para-experimentales que "modelan" hipótesis a través de la formalización digitalizada y ensayan en ellos una alternativa o "simulan" nuevos "escenarios", se encuentran bajo esta nueva episteme operativa del saber científico. Requieren un modelo generativo y la correspondencia simétrica entre ese modelo teórico formalizado y las propiedades del objeto real (o del tipo de descripción simplificada que se haga de él). Los primeros desarrollos de esta ingeniería matemática computacional, surgida hacia mediados de siglo XX durante la Segunda Guerra Mundial en EEUU, son los que han posibilitado el surgimiento de la complejidad en el discurso científico. $Y$, a su vez, éstos son hoy los recursos metodológicosinstrumentales ad $h c^{8}$ que permiten procesar el objeto como un "sistema complejo"9 . Una ingeniería que manipula la "complejidad" mediante un conjunto de instrucciones precisas susceptibles de formalización. Esta mecánica permite el tratamiento de muchos niveles de información y la observación de cómo estos niveles trabajan unidos; asimismo, da cuenta de las interacciones dinámicas que no sólo unen las partes con un todo, sino que revelan las formas en que esas interacciones constituyen las partes en sí mismas.

Podría plantearse entonces, que a esta nueva episteme operativa que condiciona las formas de entender e interpretar el saber científico, le corresponde una nueva metodología (o nuevas ciencias tecnológicas) para abordar un nuevo fenómeno (complejidad) en una sociedad occidental que desde mediados del siglo pasado puede considerarse posmoderna ${ }^{10}$. Una

\footnotetext{
${ }^{6}$ Axiomatizar una teoría (o explicación científica) sería despejar, delimitar y organizar como un sistema deductivo un conjunto de proposiciones que, en esta perspectiva, generarían el hecho científico como resultado de su operación.

${ }^{7}$ En tanto elude el carácter hermenéutico de las ciencias sociales, carácter que prima por sobre la explicación. La explicación axiomática, en correspondencia con el precepto de formalización propio del orden científico físico-matemático clásico, mantiene pretensiones de capturar la totalidad del sentido en la lógica formal, excluyendo de modo expreso como "error" o doxa la contingencia, lo errático, lo local, la historicidad o la apertura sémica de la palabra, dimensiones que de por sí adquieren valor cognoscitivo para las ciencias sociales y humanas.

${ }^{8}$ La teoría informática surgió a mediados del siglo pasado basada en las ideas y los modelos de cálculo y la ingeniería de diseño de algoritmos. Hoy, a pesar de los desarrollos teóricos y técnicos, la computadora sigue siendo una máquina determinista como lo era entonces, manteniendo su competencia técnico-instrumental para la representación y estudio de la "complejidad". De hecho, por ejemplo, el Proyecto Genoma Humano ha desarrollado un nuevo programa denominado "Devolver los genomas al programa de la vida" que se reorienta desde la noción 'genoma' a la de 'biología de sistemas' al evaluar al paradigma del gen (solitario, reduccionista y lineal) como insatisfactorio para nuevos desarrollos. Así, esta nueva redefinición del objeto de estudio tiende a acercarse al enfoque de sistemas por "su búsqueda de un conocimiento de los complejos sistemas vivos". La biología de sistemas, como nuevo paradigma, crecería así sólo por su carácter de avance en la instrumentación para las biociencias (por la mejora en la rapidez del cómputo y en la capacidad de modelado que ésta significa), y a su vez y complementariamente, por el creciente interés de científicos de la física y la informática en los problemas biológicos. Ver (2005) Fox Keller, Evelyn, "De las secuencias de nucleótidos a la biología de sistemas" En Revista Ciencias, enero-marzo, No 77, UNAM, México, pp.4-15.

${ }^{9}$ Existirían dos formas de representación; una sincrónica que especifica los procesos en un bajo nivel de información, pero permite observar el comportamiento complejo y emergente a un nivel superior. Otra diacrónica, estudia cómo surgen y se desarrollan los sistemas complejos en relación con el tiempo y la reproducción de los sistemas.

10 Del uso que hago de la noción de posmodernidad debería entenderse una concordancia con la definición de sociedad post-industrial de Daniel Bell. Me refiero, en particular e indistintamente, a una "sociedad del conocimiento", una "sociedad profesional" o una "sociedad de la información" en la cual
} 
sociedad donde las tecnociencias están interrelacionadas con la ciudadanía y la cultura, con los negocios y el mercado, con el gobierno, la academia y el Estado.

De modo tal que la ciencia, como cualquier actividad humana y aún hoy más que otras, forma parte del dispositivo contemporáneo de poder en su dimensión tecnológica; y, afirmar esto no sería negar su racionalidad interna sino observar que tal racionalidad se inscribe en el proceso histórico de una sociedad que hoy es tecno-científica. Históricamente (y en las distintas culturas) la verdad siempre se ha producido gracias a múltiples imposiciones. En una sociedad tecno-científica la verdad tiene también sus efectos reglamentados de poder, su forma esta centrada en el discurso tecnológico y científico ligado a las instituciones que lo producen, en tanto es el tipo de discurso que acoge y hace funcionar la "verdad"; necesidad de verdad indispensable para la producción económica y el poder político de cualquier sociedad $^{11}$.

Si la nuestra es una sociedad tecno-científica es porque, en primer lugar, la ciencia se ha instituido como una nueva percepción de la "realidad" a través de los dispositivos socioculturales propios de la práctica científica, incentivados a partir de mediados de siglo XIX por grandes aparatos políticoseconómicos: exploraciones científicas, colecciones, museos, relatos de viaje, cartografías, publicaciones, sociedades geográficas, exposiciones industriales, cátedras, asociaciones e instituciones de divulgación científica. Una nueva voluntad de saber ${ }^{12}$ que es propia al naciente liberalismo ${ }^{13}$ y a la expansión colonial europea por todo el mundo, con la extensión de las fronteras interiores en nuestros países periféricos. Este momento histórico se corresponde con un discurso que hoy llamaríamos cientificista ${ }^{14}$ apoyado en la filosofía positivista.

A partir de la revolución industrial, en los países centrales, la producción de estos nuevos saberes comienza a vincularse de modo creciente con su aplicación, la interrelación entre ciencia, sociedad y tecnología se ha hace evidente, y será en el siglo XX, momento en el cual los enfrentamientos bélicos

\footnotetext{
la toma de decisiones ha coagulado en la decisión técnica a través de un proceso de interpenetración entre el pensamiento tecnocrático y el político, en el contexto de una nueva formación social en los países centrales. Para Bell, esta sociedad no obedecería ya a las leyes del capitalismo clásico -primacía de la producción industrial y omnipresencia de la lucha de clases-. (1991) Bell, Daniel, El advenimiento de la sociedad post-industrial, Madrid, Alianza Universidad.

${ }^{11}$ (1992) Foucault, Michel, Microfísica de poder, Madrid, Ediciones La piqueta, p.191

12 En ciertos momentos del los siglos XVI y XVII, de modo particular en Inglaterra, surge una nueva voluntad de saber. En sus contenidos, dibujaba planes de objetos posibles, observables, medibles, clasificables; al sujeto conocedor le imponía una cierta forma de mirar y una cierta función: ver más que leer, verificar más que comentar; prescribía, además, que los conocimientos deberían investirse de un nivel técnico para constituirse en útiles y verificables. (1996) Foucault, Michel, El orden del discurso, Madrid, Ediciones La piqueta, p.21 y p. 62. Esta 'voluntad de saber' da cuenta de gestos fundadores de la ciencia moderna, inseparables de la formación de la sociedad industrial y la ideología positivista que la acompaña.

13 Lasky lo reseña panorámicamente como un movimiento de revolución copernicana cuyos fundamentos y principios quedan instalados en el siglo XVI y alcanzan su apogeo en la sociedad europea en un lento y complejo proceso de más de tres siglos. Un movimiento por el cual el bienestar individual deja de ser un efecto de la acción socialmente controlada propia del mundo feudal al producirse una transposición por la cual el bienestar social va a emerger como un efecto de la acción individualmente controlada. (1979) Laski, H. J., El liberalismo europeo, México, FCE, pp.11-27.

${ }^{14} \mathrm{La}$ ciencia decimonónica se presenta de por sí "cientificista", en tanto la ciencia se traduce de modo obvio en el único canon interpretativo de la sociedad moderna.
} 
aceleran su actividad productiva y desarrollo, cuando esta interrelación parece llegar al paroxismo. Este momento de inflexión será la segunda guerra mundial y la posguerra, cuando se vuelva autoevidente la trama indisoluble entre sociedad-tecnología-ciencia, en una sociedad que ya se define por su eficiencia posmoderna. Piscitelli, al describir esta aceleración y acumulación del saber científico y tecnológico durante el siglo $X X$, señala que comparando lo que sabemos hoy con lo que sabíamos a principios de siglo XX acerca del universo, los sistemas vivientes y la sociedad, nuestra época descuella por la cantidad y la calidad de los conocimientos, no sólo están vivos el $99 \%$ de los científicos de todos los tiempos sino que la conversión de los conceptos en sus aplicaciones es de una rapidez asombrosa. ${ }^{15}$

Considerada como la revolución científica de nuestro tiempo, González Casanova entiende que las nuevas ciencias, las técnicas y las humanidades en su articulación interdisciplinaria cambiaron al capitalismo: la nueva unión de la política, la economía y la ciencia habría transformado la práctica de la ciencia, de la economía, de la política y de la guerra. Frente a esta transformación, el autor sostiene la necesidad de comprensión y dominio de las nuevas ciencias para poder poner en cuestión el por qué y de qué forma esta articulación entre ciencia y humanidades ha modificado la sociedad y al capitalismo: ¿qué significan los cambios tecnocientíficos para ejercer una crítica transformadora?, ¿en qué consisten estos cambios en el hacer y pensar del sistema/paradigma dominante? ¿cómo han reestructurado y contextualizado las relaciones de producción y de dominación? ${ }^{16}$ Para otros autores, estos cambios en la producción colectiva de conocimientos pueden ser interpretados de manera homóloga al trabajo colectivo fabril en el sistema capitalista clásico, de forma tal que se habrían tornado apropiables (como las mercancías) y ajenos a los individuos en relación a su legítima producción. Los discursos científicos y su distribución genérica estaría siendo privatizada y concentrada ${ }^{17}$.

En esta nueva configuración contemporánea de ciencia-sociedad-tecnología es donde se ubica el área multidisciplinaria de estudios sociales de la ciencia. Y, en este nuevo escenario histórico, no es casual que parte de estos estudios consideren que el desarrollo de las ciencias se encuentra asociado a lugares de poder muy diversos, desde un ducado florentino hasta una revista internacional, y postular así que los hechos científicos deben ser interpretados como dispositivos que mezclan indisociablemente la realidad y los instrumentos de conocimiento, estos mismos ligados a una sociedad determinada que los ha puesto de manifiesto, develando la historicidad en la

15 (1994) Piscitelli, Alejandro, Ciencia en movimiento. La construcción social de los hechos científicos. Tomo I, Buenos Aires, CEAL, pp 93-94. Maldonado, por su parte, señala que esta aceleración se configura institucionalmente a mediados de la década de los ' 80 , y que ésta habría permitido comprender y conocer fenómenos que en diversos dominios constituyen más del $80 \%$ y $90 \%$ de todo lo que se sabía en la historia de la humanidad. En (2001) Maldonado, Carlos E, Visiones sobre la complejidad. (Carlos E. Maldonado editor), Bogotá, El Bosque, p.7.

16 (2005) González Casanova, Pablo G, Las nuevas Ciencias y las Humanidades. De la academia a la política, Barcelona, Antropos, pp. 39-40

${ }_{17}$ Una de los posibles a tener en cuenta para resistir a estos procesos se referiría a la potenciación de la producción colectiva. En esta perspectiva, las propuestas transdisciplinarias e interdisciplinarias de Edgar Morín y Rolando García son señaladas como algunos de los antecedentes privilegiados en las alternativas de la coproducción investigativa. (2007) Bialakowsky, A; Costa, M. I.; Petrouilleau, M; Martínez Schnaider, R; López, A. L, "Capitalismo y método. Alternativas de la coproducción investigativa" en Revista Sociedad, Buenos Aires, Facultad de Ciencias Sociales UBA, No 26, pp.103124. 
producción de los hechos científicos mismos. ${ }^{18}$ En los albores de la sociedad moderna, el conocimiento experimental estableció la "neutralidad científica", nueva noción que mantiene sus envíos simbólicos o remisiones con las ideas de "universalidad" y "objetividad" científica como parte de un mismo espacio discursivo o constructo sociocultural ${ }^{19}$. Para ello, debió excluir a la economía, la política y la religión, y asumir como evidente que la cultura y la sociedad no intervenían en la percepción de los "puros hechos naturales". Una nueva sensibilidad que al fijar su identidad en la asepsia del experimento expulsó, entre otros, a los dispositivos de poder que obraban en ella ${ }^{20}$. Así, estos estudios que vinculan a la práctica científica con la sociedad (en la diversidad y disparidad de sus formas) hacen posible una "epistemología ampliada" al reintegrar la actividad científica a su contexto de múltiples atravesamientos productivos.

Las corrientes en sociología del conocimiento que emergen a partir de fines de la década de los años setenta implicaron un progresivo quiebre del paradigma mertoniano. Para la sociología clásica de la ciencia, el carácter universal de las prácticas científicas era un presupuesto revalidado en el ethos científico moderno postulado por Merton, para quien existían cuatro conjuntos de imperativos institucionales: el universalismo, el comunismo, el desinterés y el escepticismo generalizado ${ }^{21}$. El debate que atravesó la sociología de la ciencia se definió entre los críticos a la tesis de Merton y quienes las habían enriquecido y apoyado empíricamente desde la escuela de Columbia. La posición crítica, que cobró importancia creciente, se basó en el postulado de que por causas internas y externas a la propia actividad científica, ésta se configura de forma similar a las pautas y los valores dominantes de la más amplia sociedad en la que la ciencia se ubica ${ }^{22}$, estableciendo así la

18 (2010) Jensen, Pablo, "Mitos e ilusiones de la ciencia", Le mond diplomatic, Capital intelectual, Año XI, No132, p.28.

${ }^{19}$ Espacio discursivo entendido como un conjunto de identidades diferenciales que se constituyen en, y sólo a través de la relación con otras identidades. Un juego de diferencias que supone síntesis y remisiones o reenvíos. (1977) Derrida, Jacques, Semiología y gramatología en Posiciones, Valencia, PreTextos, p. 35

20 (2010) Díaz, Esther, Las grietas del control. Vida, vigilancia y caos, Biblos, Buenos Aires, pp. 69-70.

${ }^{21}$ Merton identificó los que serían los factores propios del quehacer científico que habrían permitido la constitución de la ciencia moderna en tanto institución social y que, a su vez, garantizaban su vigencia como tal. En su tesis de los C-u-d-e-o-s, en correspondencia con su funcionalismo clásico, postula una explicación normativa basada en valores morales. Así, el universalismo hallaría inmediata expresión en el canon de que las pretensiones a la verdad deben ser sometidas a criterios impersonales preestablecidos. El comunismo responde al postulado de que los hallazgos de la ciencia son un producto de la colaboración social y deben ser asignados a la comunidad. La exigencia de desinterés responde al carácter público y contrastable de la ciencia, por lo tanto su traducción a la práctica se hallaría sostenida por la necesidad de los científicos de rendir cuentas y en primera instancia ante sus iguales. Por último, el escepticismo organizado sería un mandato metodológico e institucional, por el cual el investigador científico no debe preservar abismos entre lo sagrado y lo profano, entre lo que exige respeto acrítico y lo que puede ser analizado objetivamente, se refiere en particular a la religión, pero señala también la situación contemporánea de los grupos económicos y políticos. (1977) Merton, R. K: "La estructura normativa de la ciencia" en La sociología de la ciencia. Vol. 2, (Recopilación e Introducción N. W. Storer), Alianza, Madrid, pp.355-368

${ }^{22}$ En cuanto a su aspecto normativo, la posición crítica se centraría en el hecho de que éste no daba cuenta alguna de las conductas reales de los científicos. El universalismo sería un concepto tan genérico que su concreción dependería de los valores de la sociedad en donde opera; además, la vida científica no se organizaría como una comunidad de iguales que juzga productos y distribuye los recursos de acuerdo a criterios impersonales, sino sería más bien una élite que acapararía los medios y enjuiciaría las contribuciones con criterios particulares; en relación al comunismo el "secreto" no sólo afectaría a las actividades científicas del mundo industrial o militar sino que afecta a la globalidad del quehacer científico dada las formas con los que los científicos organizan sus relaciones sociales y publicaciones. En cuanto al desinterés, sostiene que existen otros componentes que afectan las conductas de los científicos como la intensa competencia por publicar, las luchas por la prioridad, las tácticas para 
posibilidad de repensar a la actividad científica en su carácter de práctica social inscripta en un proceso de producción científica, y a este proceso en una sociedad histórica particular.

Para Kreimer ${ }^{23}$ estas nuevas perspectivas, enroladas genéricamente en la sociología constructivista del conocimiento, posibilitaron dos movimientos imposibles de efectuar bajo la sociología clásica de la ciencia, derivadas de la incapacidad de ésta para vincular el contexto social de emergencia de las prácticas científicas con las relaciones internas en el ámbito de producción o fabricación de conocimientos y con los contenidos mismos de esos conocimientos. El primer movimiento fue ubicar a los procesos de producción de conocimientos en un espacio social, un campo de trabajo científico atravesado por las dinámicas y determinaciones de la sociedad local en sus dimensiones social, simbólica y material. El segundo fue penetrar dentro de los espacios donde el conocimiento resulta efectivamente producido, negociado, certificado y validado para lograr la identificación de actores, del contenido de sus prácticas y de los recursos que movilizaban. Dentro de estas nuevas corrientes constructivistas ya quedan inscriptos los estudios sobre tecnología ${ }^{24}$, en este sentido el trabajo "Networks of Power. Electrification in Western Society, 1880-1930" $(1983)^{25}$ de Thomas Hughes puede considerarse inaugural, con un encuadre sociotécnico.

Latour, planteará que estos estudios no se definen por la extensión de las explicaciones sociales de la ciencia y que se encuentran alejados de las filosofías normativas de la ciencia y del interés de desenmascarar las pretensiones de ésta. Este abordaje, al hablar de práctica científica, habría construido un análisis "más realista" de la ciencia-en-desarrollo. Una etnografía en el laboratorio científico que les permite re-conocer que los "hechos científicos" son claramente inventados; por lo tanto, en lugar de hablar de "objetos científicos" y de "objetividad", estos estudios hablan de "no humanos" socializados en el laboratorio y con quienes los científicos empezaron a intercambiar propiedades. El caso más conocido relata cómo Pasteur hace sus microbios y cómo los microbios 'hacen su Pasteur'26. Así, a su vez, los microbios de Pasteur no serían los nuestros en tanto al haber sido investidos de instrumentos, aparatos y teorías diferentes algunos se habrían transformado en entes híbridos tales como un virus. En esta perspectiva, nuestra sociedad moderna no habría funcionado según las grandes divisorias que funda su sistema de representación: la divisoria entre naturaleza y cultura nunca habría existido y en la práctica los modernos habrían construido sólo

conseguir fondos y la creciente interpenetración entre ciencia básica, aplicada y desarrollo tecnológico. Y de modo categórico, en relación al escepticismo organizado, señalan que los científicos distinguen entre lo sagrado -sus propias contribuciones- y lo profano -las que se oponen a sus tesis- estableciendo una relación afectiva y emocional con sus teorías. (1994) Lamo de Espinosa, E Gonzáles García, J Torres Albero, C, La sociología del conocimiento y de la ciencia, Alianza, Madrid, pp. 465-471.

23 (2000) Kreimer, Pablo: "Ciencia y periferia: Una lectura sociológica" En La ciencia en la Argentina entre siglos, Buenos Aires, Manantial, pp. 187-202.

${ }^{24}$ (2005) Bijker, W. E, "¿Cómo y por qué es importante la tecnología?", REDES, Vol. 11, No 21, Buenos Aires, pp.19-53

25 En este trabajo se relata el complejo proceso de electrificación de algunas ciudades de Europa y de América del Norte (Berlín, Londres y Chicago), en él Hugues expone las diferentes fases en las que estructura su concepción del desarrollo de los sistemas tecnológicos.

${ }^{26}(2000)$ Latour, Bruno, La esperanza de Pandora. Ensayos sobre la realidad de los estudios de la ciencia, Barcelona, Gedisa, pp. 137-173. 
objetos híbridos, inclasificables en esta dicotomía (bacterias, enzimas, microprocesadores, virus de sida, agujeros de la capa de ozono, robots...). ${ }^{27}$

La propuesta precedente intenta alejarse del "pacto modernista", tejiendo desde la reflexión de la práctica científica un recorrido inverso al de la institución de la ciencia moderna. Así, desde el punto de vista de los science studies no tendría sentido hablar de epistemología, ontología, psicología y política como entidades separadas porque están supuestas en una concepción de ciencia moderna que se basa en el pre-supuesto de grandes dicotomías: "ahí afuera" equivaldría a la naturaleza; "ahí adentro" a la mente; "ahí abajo" a lo social y "ahí arriba" a Dios. ${ }^{28}$ La línea divisoria entre sujeto y objeto de conocimiento sería la dicotomía moderna fundante que es puesta en cuestión por Latour como no obvia ni inocente. Un esquema que, conforme la modernidad ha ido desplegándose ha hecho que la subjetividad y la objetividad se hayan convertido en amenazantes entre sí, perdiendo su espíritu liberador original. ${ }^{29}$ A su vez, Latour diagnostica que hoy la práctica de la ciencia se habría politizado hasta tal punto que ya no sería posible distinguir los objetivos de la política ni los de la ciencia.

Podría concluirse, entonces, que así como la ciencia hacia mediados del siglo pasado des ocultó su pertenencia a la triada ciencia-tecnología-sociedad al producirse un crecimiento exponencial de sus productores, productos y aplicaciones, también los estudios sobre su actividad se multiplicaron. Un movimiento de inversión por el cual aquella institución moderna que producía las explicaciones se convirtió en el problema a explicar desde sus más diversos aspectos: sociales, éticos, políticos, históricos, epistémicos, simbólicos, discursivos... El campo de los estudios de la complejidad, en contraste con estas visiones contemporáneas (y de modo casi tautológico) parece presentarse como un movimiento en bucle sobre la ciencia misma.

\section{Un recorrido recursivo: de la ciencia a las ciber-ciencias}

Desde la aparición de las ciencias de la complejidad con sus difusos bordes disciplinarios, su posterior ejercicio reflexivo filosófico a través del pensamiento complejo y la epistemología de la complejidad, y en su actual ligadura múltiple científica, epistemológica e incluso ontológica, puede postularse un interés deconstructivo en afinidad con los estudios contemporáneos de la ciencia. Pero, a diferencia de éstos, la complejidad como cosmovisión se vale de programas, teorías y análisis de base científica para efectuar esta implícita primero, y luego expresa, puesta en cuestión de la modernidad. Líneas de investigación científica que han afectado a la modernidad en sus presupuestos fundacionales desde la producción científica misma, emergencia desde el interior del discurso científico que permite poner de relieve el carácter controvertido de la producción tecnocientífica.

\footnotetext{
${ }^{27}$ (1993) Latour, Bruno, Nunca hemos sido modernos. Ensayo de antropología simétrica, Madrid, Debate, pp.24-27

${ }_{28}$ Ibid, pp.26-29

${ }^{29}$ Idem, pp. 352-353.
} 
Esto no significa despojar a estas nuevas disciplinas científicas de su contexto político de emergencia histórica, sino por el contrario, enfatizarlo; pero efectuando una distinción con la posición que sólo pone de relieve el papel de la cibernética en el proceso de crecimiento exponencial de poder científico en nuevos saberes de mando, control, gestión y comunicación, surgidos en el complejo político/militar/científico durante la Segunda Guerra Mundial. Así, en acuerdo con Fox Keller ${ }^{30}$ y González Casanova ${ }^{31}$, la hipótesis propuesta es que las "ciberciencias" se desarrollaron en respuesta a la inviabilidad creciente de los regímenes de poder tradicionales. Pero, para ello, debieron obrar tácitamente en contra de ciertos presupuestos de la modernidad. Por "ciberciencias" debiera entenderse un conjunto de disciplinas desarrolladas hacia mediados del siglo XX en EEUU: teoría de la información, cibernética, análisis de sistemas, investigación operacional y ciencia de la computación. Estas áreas habían mantenido como objeto de trabajo común el análisis de sistemas complejos, un mismo vocabulario conceptual en este análisis (retroalimentación, información, causalidad circular) e igual modo de representación de los sistemas complejos como redes o circuitos interactuantes. $^{32}$

Para los científicos inscriptos en estas disciplinas durante la Segunda Guerra, la complicación del mundo se tornó obvia, los intercambios políticos, militares, económicos se hicieron cada vez más intensos y complejos. Megaproyectos militares con sistemas de personal desmesuradamente grandes: científicos de diversas disciplinas (ingeniería, matemática, física, química), múltiples técnicos de las universidades y técnicos de la industria, miles de personas en oficinas administrativas, numerosas empresas contratistas y sub- contratistas, innumerables proveedores y técnicos militares. Estos proyectos de gran escala, con un grado de complejidad desconocida hasta entonces, signaron el contexto institucional de emergencia de las ciberciencias. Nuevas formas de institucionalidad científico- tecnológica que se prolongarán en la posguerra de la guerra fría con sus estilos corporativos como la Rand corporation ${ }^{33}$ y que se replicaron rápidamente como el modelo de construcción de la política científica en otros países centrales. Transformación que Solla Price llama la big science $^{34}$ y que ubica a la ciencia disputando la hegemonía de la escena

\footnotetext{
${ }^{30}$ (2000) Fox Keller, Evelyn, Lenguaje y Vida. Metáforas de la biología en el siglo XX, Buenos Aires, Manantial, p. 93.

${ }^{31}$ (2005) González Casanova, Pablo, Op. Cit., p. 40 y p. 82

32 (2000) Fox Keller, Evelyn, Op. Cit., p. 92.

33 La corporación Rand, fundada en 1948 con financiación de la Fuerza Aérea de EE.UU, desarrolló técnicas de análisis de sistemas para la evaluación de sistemas de armas. Otra corporación de similares características es la Mitre Corporation, fundada en 1958 con fondos de la fuerza aérea, esta última se concentró en la administración de sistemas de ingeniería para los grandes proyectos militares. Sobre la Rand ver sitio web oficial: http://www.rand.org/about.html. Sobre la Mitre ver sitio web oficial: http://www.mitre.org/about/history.html.

34 Las instalaciones científicas básicas se habrían sobredimensionado de tal manera que fueron comparadas con las pirámides de Egipto o las catedrales medievales; los gastos de personal e inversión se convirtieron en un aspecto de gran importancia para la economía estadunidense. La magnitud que la ciencia habría adquirido era tan manifiesta que fue llamada "ciencia grande" en oposición a la ciencia desarrollada hasta entonces. En la época de la "pequeña ciencia" habría existido un notorio recelo contra la actuación política de los científicos, en este nuevo período poder y ciencia alcanzan una relación que ubica al científico en un grado creciente de opulencia y popularidad, como lo imagina el autor: "Cuando vi por primera vez al protagonista de la historia de Superman, que había identificado hasta entonces con un jugador de rugby 'típicamente americano', convertirse en un físico nuclear típicamente americano, sentí que había terminado una época y que el próximo presidente podría muy
} 
política estadounidense. Hoy resulta dramáticamente emblemático el Proyecto Manhattan, pero este tipo de política que involucró a 130 mil personas, un costo actual de 20 mil millones de dólares y colaboración multinacional, será el modelo que se impondrá a posteriori; proyectos tales como el contemporáneo Proyecto Genoma Humano el que lo quintuplicó en inversión, y otros en comunicaciones (telemática) e inteligencia que hoy poseen cifras billonarias.

Esta nueva doctrina de política científica se encuentra delineada por V. Bush ${ }^{35}$ en su informe "Ciencia, la frontera sin fin" $(1945)^{36}$ redactado en su calidad de asesor en materia científica del presidente Roosevelt. El texto expresa una confianza casi religiosa en el desarrollo tecnológico basado en la ciencia, preso del optimismo cientificista de la naciente posguerra (que Bush compartía con la mayoría de sus colegas). En él, propone la transferencia al ámbito público de los conocimientos tecnológicos producidos durante la guerra en el ámbito militar y sugiere acciones de asistencia y promoción a la investigación nacional en las áreas de seguridad, salud, educación e industria. Pero, su aporte sobresaliente es la propuesta de una fundación que sería el eje de una política científica del estado nacional, con un claro énfasis en la investigación básica. La ciencia se presentó así como un recurso político nacional del estado. En los hechos, el texto habría jugado un papel importante en la transformación de la ciencia desde el reducto privado en el que se encontraba antes de la guerra al lugar público central que llegó a ocupar en los Estados Unidos de posguerra. De este modo, la big science fue apropiada por el contexto sociocultural norteamericano hasta ser políticamente relevante. ${ }^{37}$

La "gran ciencia" redefinió todo un entramado de relaciones sociales: entre la industria y el Estado, entre la comunidad científica, la técnica y el Estado, entre civiles y militares, entre los distintos organismos de gobierno y, en definitiva, entre la tecnología y la sociedad ${ }^{38}$. En este entorno, el enfoque de las nuevas ciencias cibernéticas se desarrolló en formas novedosas, exitosas y sin precedentes en el período 1939-1960 alcanzando su punto máximo de popularidad durante la primera presidencia de Lyndon Johnson (1963-1969). Posteriormente, con los reveses de la guerra de Vietnam, el surgimiento del movimiento contracultural y la limitada capacidad para hacer frente a los problemas urbanos relativos a factores políticos y sociales, esta perspectiva

bien ser un ex científico" (1973) Solla Price, Derek J., Hacia una ciencia de la ciencia, Barcelona, Ariel, p.172 [las cursivas son mías]

35 Vannevar Bush, ingeniero egresado del MIT, durante la I Guerra Mundial trabajó en la Marina como ingeniero, formó parte del Comité de Investigación para la Defensa (CNDR) y fue presidente de la Oficina de Investigación y Desarrollo Científico (ambos organismos nacionales creados ad hoc durante la Segunda Guerra). Como científico se abocó al desarrollo del "analizador diferencial", y su modelo "memex" es considerado hoy un antecedente del hipertexto y de la Internet. Norbert Wiener fue su mentor en matemáticas en sus primeros días como profesor de ingeniería, y a su vez, Bush lo convocó desde el Comité de Investigación (CNDR) como investigador universitario del MIT para trabajar en el problema de seguimiento de objetivos de ataque (primero instrumentado con óptica y luego con radar). Se intentaba solucionar los problemas de predicción de posiciones futuras de estos objetivos, el cálculo de balística, y la dirección de las armas para destruirlos. Ver Mindell, David: Cybernetics. Konowledge domanins in engineerin systems. Artículo disponible en web: http://web.mit.edu/esd.83/www/notebook/Cybernetics.PDF.

${ }^{36}$ (1999) Bush, Vannevar, "Ciencia, la frontera sin fin. Un informe al presidente, julio de 1945", REDES, Vol. VI, No. 14, pp. 89-137.

37 (1999) Jamison, Andrew: "Comentarios al dossier", REDES, Vol. VI, No. 14, pp. 146-148.

38 Ver Roland, A: Technology and War. Artículo disponible en web: http://www.unc.edu/depts/diplomat/AD_Issues/amdipl_4/roland.html. 
habría perdido su gran popularidad, pero las relaciones entre la sociedad estadounidense y la tecnología ya se encontraban redefinidas ${ }^{39}$.

Este podría considerarse el contexto socio político de emergencia de las ciberciencias y de sus contenidos en relación con la aparición de una sociedad post industrial o de eficacia posmoderna, donde según Bell, los problemas sociológicos e intelectuales más importantes prácticamente habrían quedado circunscriptos a la dirección de los sistemas a gran escala. Es decir, a "un amplio número de variables en interacción", las que debían ser coordinadas para poder llegar a resultados específicos ${ }^{40}$. Sin embargo, la filosofía instrumental que subyace al contexto socio político de emergencia de estas nuevas ciencias no debiera superponer, y solapar así, una pujante filosofía organísmica del ser vivo de la que se valieron sus formas epistémicas. Una filosofía que se sustentaba en la tesis de que las características exclusivas de los organismos vivos no se debían a su composición físico-química sino a su organización.

En la primera mitad del siglo XX había sido habitual considerar que el principal problema de la biología era el de la "organización viviente". Bajo el discurso biológico pre- molecular (embriología/biología del desarrollo) en el que afloraron las ciberciencias, se exhibe de forma manifiesta una cosmovisión organicista, base de un imaginario científico generalizado que piensa a los sistemas en tanto organismos biológicos. El organicismo se constituye así en el marco epistémico en el cual se hacen indiscernibles las contribuciones que provienen del contexto socio político y el componente cognoscitivo intrínseco ${ }^{41}$. Esta ideología organicista, a su vez, da cuenta de una implícita interpelación a la modernidad en el proceso de emergencia de estas nuevas ciencias.

\section{El organicismo: fisura impensada de la modernidad en la nueva factibilidad del poder}

El concepto de organismo ocupa una posición central en la biología, análoga a la que el concepto de energía ocupa en la física [L. von Bertalanffy] ${ }^{42}$

\footnotetext{
39 (2000) Hugues, Agatha y Hugues, Thomas, Introducccion en Sistems, Experts, and Computers. The system approach in Management and Engineering, World War II and after, MIT press, Cambridge, Mass., pp.1-5

40 De allí que para Daniel Bell desde 1940 haya habido un notable desarrollo de nuevos campos cuyos resultados se aplican a los problemas de la complejidad organizada -tal y como la define Weaver-: teoría de la información, cibernética, teoría de la decisión, teoría de juegos, teoría de la utilidad, procedimientos estocásticos y las nuevas técnicas específicas derivadas de ellos (la programación lineal, la teoría estadística de la decisión, las aplicaciones en cadena de Harkov, los cálculos de azar de Montecarlo y las soluciones mínimas que se utilizan para predecir los resultados alternativos de elecciones diferentes en situaciones estratégicas...). (1991) Bell, Daniel, Op. Cit., p.47.

${ }^{41} \mathrm{El}$ concepto de 'marco epistémico' si bien presupone una distinción precedente entre paradigmas sociales y paradigmas epistémicos, se refiere al hecho de que en un período histórico y en una sociedad particular se presenta la hegemonía de un marco epistémico donde se hibridan ambos tipos de paradigmas transformándose en una ideología. (1994) Piaget, Jean y García, Rolando, Historia y psicogénesis de la ciencia, México, Siglo XXI, p. 234. Citado a su vez en (1997) García, Rolando, La epistemología genética y la ciencia contemporánea. Homenaje a Jean Piaget en su centenario, Gedisa, Barcelona, pp.42-43

42 Ludwing von Bertalanffy, quien sistematizó y formuló una "teoría general de sistemas" (TGS) había participado activamente hacia finales de la década del veinte en la postulación del programa organísmico para la biología teórica.
} 
La primera definición en el uso técnico moderno de sistema, y la primera definición prototípica de un cyborg [cibernético+organismo] ${ }^{43}$ se encuentra, según Fox Keller, en el "Informe de la marcha de la Comisión de Diseño de los Sistemas de Defensa Aérea", un reporte fechado el I de mayo de 1950 para la Junta de Asesoramiento Científico del Estado Mayor de la Fuerza Aérea de los Estados Unidos. En este texto un sistema, y el SDA en particular, es concebido como un organismo:

El Sistema de Defensa Aérea tiene puntos en común con muchos de los diferentes tipos de sistemas. Pero también forma parte de una categoría particular de ellos: la de los organismos. Esta palabra significa 'una estructura compuesta de distintas partes constituidas de tal forma que su funcionamiento y sus relaciones recíprocas están gobernadas por el todo'. El acento no sólo se pone en el patrón y el ordenamiento, sino también en lo que determina la función, un atributo deseado por el Sistema de Defensa Aérea. El sistema de Defensa Aérea, por tanto es un organismo (...) Todos ellos [los organismos animados, parcialmente animados e inanimados] tienen en común los siguientes elementos: componentes sensoriales, instrumentos de comunicación, dispositivos de análisis de datos, centros de evaluación, directores de acción y efectores, o agencias de ejecución. Los organismos también tienen la capacidad de desarrollo o crecimiento (...) por otra parte es también necesario proveerlos de material (...) La función de un organismo consiste en interactuar con otros organismos y modificar las actividades de éstos, generalmente para alcanzar alguna finalidad definida ${ }^{44}$

Para quienes escribieron el reporte, como lo infiere Fox Keller, los rasgos centrales de un sistema eran los del organismo biológico: la función, la coordinación, la interdependencia y la intencionalidad.

La noción de sistema y organismo en su yuxtaposición puede ser referida al diseño específico de un sistema como el SDA, pero también es posible registrarla cuando se examina cómo se produjo este particular conjunto de técnicas de ingeniería durante la Segunda Guerra Mundial. Un nuevo instrumento de percepción, el radar, dio lugar a un nuevo enfoque en la

\footnotetext{
43 En una ironía de la historia de la ciencia estadounidense, cuatro décadas después, según Donna Haraway todos ya seríamos "quimeras, híbridos teorizados y fabricados de máquina y organismo; en una palabra, somos cyborgs" Para esta historiadora y filósofa de la ciencia las ciberciencias habían incrementado el régimen de poder convencional, pero en este manifiesto utópico recreará en el concepto de cyborg un discurso crítico, emancipatorio e hipertecnológico. Una exacerbación de la cibernética que, al ser despojada de su ideología organicista de origen, le permitirá argumentar en favor del cyborg como "una ficción que abarca nuestra realidad social y corporal y como un recurso imaginativo sugerente de acoplamientos muy fructíferos", que puede contribuir "a la cultura y a la teoría feminista socialista de una manera postmoderna, no naturalista, y dentro de la tradición utópica de imaginar un mundo sin géneros, sin génesis y, quizás, sin fin". Y si, "la política holística organísmica y de organismos depende de las metáforas de la resurrección e, invariablemente, se basa en los recursos del sexo reproductivo [Ella] Quisiere sugerir que los cyborgs tienen más que ver con la regeneración y desconfían de la matriz reproductora y de la mayoría de las natalidades". Además, como este nuevo ente sería capaz de transgredir las tradiciones corporales basadas en dicotomías jerárquicas, la historiadora concluye que prefiere... "ser un cyborg que una diosa". (1991) Haraway, Donna: "A Cyborg Manifesto: Science, Technology, and Socialist-Feminism in the Late Twentieth Century," in Simians, Cyborgs and Women: The Reinvention of Nature New York; Routledge pp.149-181[las cursivas son mías]

44 "Progress Report of the Air Defense Systems Engineering" (1950), citado en (2000) Fox Keller,Evelyn Op. Cit. pp. 96-97.
} 
ingeniería de sistemas. Como señala Mindell, antes de la Segunda Guerra todo era exactamente "la suma de sus partes", pero el radar, el ruido y la retroalimentación habrían complejizado tal simplicidad en tanto en un sistema de control dinámico cada componente afecta a los demás. Así, Norbert Wiener y el equipo del Radiation Lababoratory (MIT ${ }^{45}$ debieron abrevar en el carácter biológico de los organismos para poder incorporar a las máquinas la aptitud de un comportamiento emprendedor y premeditado, propio de las "maquinas intencionales" o sistemas auto-organizados (autodirigidos y autocorrectivos) necesarios para el rastreo de objetivos. ${ }^{46}$

Esta idea orgánica es tan fructífera en su traducción matemática que Norbert Wiener, en su trabajo "Cibernetics: or, Control and Communication in the Animal and Machine" (1948) ${ }^{47}$, argumenta a favor del carácter intercambiable entre las maquinas conocidas como transductores de insumos y productos múltiples y los organismos biológicos. Numerosos tipos diferentes de sistemas pueden ser estudiados de acuerdo a los principios de la retroalimentación, el control y la información. Concibiendo analogías tales como el comportamiento de los nuevos equipos digitales y el sistema nervioso de los seres humanos, el programa de trabajo de Wiener posibilitó extender así ese conocimiento a los sistemas biológicos, fisiológicos, psicológicos y sociales, ya sea como idea heurística o en sus expresiones formalizadas.

Esta expansión de las ideas de las ciberciencias se vio institucionalizada en las diez Conferencias J. Macy realizadas en el período 1946- 1953. Centralmente, en éstas se pretendía la difusión de las nuevas ideas surgidas durante la guerra al campo de otras disciplinas físico-naturales y al de las ciencias sociales, su objeto era producir ligaduras interdisciplinarias. Las conferencias fueron impulsadas por Wiener y contaron con la participación del establishment científico de la época. Un grupo con una muy importante influencia en conexiones, contactos y fijación de agendas de investigación. Participaron G. Bateson, C. Shannon, Bigelow, von Bonin, Parsons, Merton, P. Lazarsfeld, W. Mc. Culloch, M. Mead, R. Ashby, Ackerman, J. von Neumann, Northorp, Rosemblueth, von Foerster, Wiener, Lewin, Erikson, Harrower, Pitts, y L. Kubie entre otros. Los temas discutidos iban desde la piscología de la Gestalt a la visión; los mecanismos teleológicos y la causalidad circular; analogías entre la máquina y los organismos; el lenguaje y el cerebro debatidos en tanto máquina digital o analógica; la sabiduría; los autómatas; los sistemas biológicos y sociales; el concepto de campo, el de orden y el de caos; neurosis y locura; el papel del observador y la comunicación humana, entre otros ${ }^{48}$.

\footnotetext{
${ }^{45}$ El Laboratorio de Radiación del Massacchusetts Institute of Technology (MIT) junto con el Laboratorio Bell (Bell Telephone Laboratories) su adversario y colaborador, son el eje académico en torno al cual se desarrolla la nueva ingeniería de sistemas y la cibernética durante la Segunda Guerra Mundial.

${ }^{46}$ Ver (2000) Mindell, David: "Automation's finest hour: Radar and System integration in World War II" En Hugues, Agatha y Hugues, Thomas, Sistems, Experts, and Computers. The system approach in Management and Engineering, World War II and after, MIT press, Cambridge, Mass., pp. 28-56

47 (1965) Wiener, Norbert, Cibernetics: or, Control and Communication in the Animal and Machine, MIT Press, Cambridge, Mass. En este texto, Wiener acuña el concepto de cibernética. Lo hace en base a la

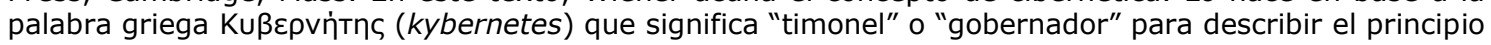
que rige o dirige un sistema (p. 11).

${ }^{48}$ Ver sitio web oficial de la American Society for Cibernetics:

http://www.asccybernetics.org/foundations/history/MacySummary.htm
} 
Marget Mead ${ }^{49}$ y Gregory Bateson ${ }^{50}$ serían quienes desde las ciencias sociales habrían alentado este tipo de iniciativas interdisciplinarias. Si bien, Wiener como matemático con experiencia en las ciencias físicas, mantuvo su escepticismo en relación al desarrollo de la cibernética en las ciencias sociales. Alegó cuestiones metodológicas y epistemológicas como la ineficacia de la aplicación de técnicas matemáticas estadísticas en esas áreas y la dificultad por el tipo de vinculación con el objeto que caracteriza a la investigación social. ${ }^{51}$. Stengers, advierte que una réplica indirecta a estas objeciones de Wiener fueron las tesis aparecidas en el campo de las ciberciencias, que en concordancia con la visión orgánica, sostienen la unión indisoluble entre el observador y el objeto. El acoplamiento entre Sujeto y Objeto no constituiría un obstáculo, sino por el contrario, establecería una definición distintiva entre la física y las ciencias de los sistemas complejos ${ }^{52}$. Definición no sólo distintiva sino también singular en tanto horada sobre uno de los presupuestos centrales del paradigma moderno (visión que construyó y naturalizó como arbitrario social la noción de sujeto de conocimiento y de objeto conocido como dos instancias separadas). ${ }^{5}$

Los desarrollos teóricos de John von Neumann ${ }^{54}$ responden asimismo a la analogía entre el organismo biológico y los sistemas, llevándola al máximum en la búsqueda de una efectiva homología. Este matemático intentó caracterizar computacionalmente al organismo vivo. La "la teoría de los autómatas celulares" resultó un modelo exitoso que en su formulación elemental se refiere a un conjunto de células-espacio-celda que pueden adoptar un número finito de estados y evolucionan en pasos, según reglas dadas. El razonamiento axiomático fue: a) la auto-reproducción, se lleva a cabo por una máquina bioquímica altamente compleja b) por lo tanto, el comportamiento de esa

\footnotetext{
49 Wiener, en la introducción a su libro Cibernética, señala como referente en las ciencias sociales a la pareja al referirse a los coloquios de la Fundación Macy (p.18); páginas más adelante, dará cuenta de la solicitud reiterada de ambos para extender a las ciencias sociales los desarrollos cibernéticos (p. 24). En 1967, la antropóloga Margaret Mead (apodada la "madre de la cibernética") redacta para la Sociedad Americana para la Cibernética (SCA) a partir de una sugerencia de Bateson, el documento "Cibernética de la cibernética". En él propone que esa institución debería considerarse un organismo cibernético y aplicar así las ideas y técnicas cibernéticas a su propia organización y funcionamiento. Heinz von Foerster, a su vez, fue quien le sugirió a Mead el título, el que se convertiría más tarde en el nombre extendido de la cibernética de segundo orden. Extracto del documento disponible en: http://www.asccybernetics.org/CofC/wp-content/uploads/2010/08/mead.html.

50 Bateson es considerado polifacético: biólogo y antropólogo, con incursiones en la psicología, la comunicación y la epistemología. Durante la Segunda Guerra trabajó para los servicios de la Armada en acciones de inteligencia en torno a la comunicación (propaganda y desinformación).

51 Ibid pp. 24-25.

52 (1991) Stengers, Isabelle, "Una lectura de Bateson" En Bateson. Primer inventario de una herencia (Yves Winkin coord.), Nueva Visión, Buenos Aires, pp. 105-116.

${ }^{53}$ Kant es quien lo plasma, su sistema será el fundamento riguroso para las "leyes de la naturaleza" de la ciencia newtoniana. El filósofo parte de la convicción de que la ciencia existe y de esa convicción va a sacar sus conclusiones. Concibe las condiciones a priori (y por ende necesarias) de la experiencia únicamente del lado del Sujeto. Una teoría del sujeto trascendental que distancia al Objeto (y lo pasiviza) al negarle cualquier condición de experimentalidad.

${ }^{54}$ Trabajó en los fundamentos de la teoría de conjuntos y en los fundamentos matemáticos de la mecánica cuántica, a él corresponde (en coautoría con Oskar Morgenstern) la teoría de los juegos: "Theory of Games and Economic Behavior" (1944). En el momento en que se interesó en la informática (1943) ya era un científico internacional famoso que había hecho contribuciones a las matemáticas, fisica, y la economía. Durante y después de la Segunda Guerra Mundial fue un asesor científico y estadista, comisionado de la energía atómica (Manhattan Projet) y el principal asesor científico de la Fuerza Aérea en el desarrollo de misiles balísticos (Ballistic Research Laboratories). Al respecto, cabría agregar que en contraste con Wiener y después de Hiroshima, von Neumann siempre habría expresado satisfacción por su participación militar. Él, a diferencia de Wiener, había sido responsable político directo en la determinación de objetivos de destrucción atómica.
} 
máquina es descriptible como una secuencia lógica de etapas c) si el algoritmo se puede llevar a cabo por alguna máquina, esa máquina es la de Turing (capaz de ejecutar cualquier actividad matemática representable por un algoritmo). Von Neumann consiguió bosquejar una máquina Turing autoreproductiva utilizando los autómatas celulares. Como testimonia Claude Shannon, la teoría de los autómatas no era un área de investigación claramente definida, las cuestiones que involucraban iban desde los problemas lógicos matemáticos de Gödel -en relación a las máquinas de Turing y los procedimientos de decisión- hasta las preguntas de la duplicación y de diversos fenómenos biológicos en una máquina: la adaptación, la auto-reproducción y auto-reparación. ${ }^{55}$

El interés de von Neumann en la computadora como instrumento científico se originó en la necesidad de una herramienta 'más poderosa' para resolver ecuaciones diferenciales asociadas a su trabajo durante la Segunda Guerra. Pero, mucho antes del término de ésta él ya había advertido el valor que estos nuevos equipos podrían tener para resolver una amplia gama de problemas (especialmente los relativos a problemas no lineales). El proyecto de informe sobre el EDVAC (Electronic Discrete Variable Automatic Computer) que von Neumann escribió en 1945, fue el primer relato sobre una computadora con programa almacenado. Entre 1946 y 1948, presentó en coautoría la primera descripción detallada del diseño y la programación de un ordenador. El dispositivo EDVAC se constituyó en el patrón arquitectónico del ordenador electrónico moderno. ${ }^{56}$

Claude Shanonn ${ }^{57}$ es considerado el iniciador de la teoría de la información, si bien las mediciones estadísticas de una cantidad denominada "información" e independiente de su significado, se habrían iniciado en EEUU en la década del 30. La información así concebida se crea al ser redefinida como 'el negativo de la cantidad formalmente idéntica a la entropía termodinámica'. Esta idea es tributaria de la necesidad de los Laboratorios de Telefonía Bell por buscar nuevas formas para maximizar la eficiencia y confiabilidad de las transmisiones por cables. En la introducción a "A mathematical theory of communication" (1948), Shannon advierte:

El problema fundamental de la comunicación es el de reproducir en un momento exacto o aproximado un mensaje seleccionado en otro punto. Con frecuencia los mensajes tienen un significado, es decir que se refieren o están relacionados de acuerdo con algún sistema con ciertas entidades físicas o conceptuales. Estos aspectos semánticos de la comunicación son irrelevantes para el problema de ingeniería. El aspecto significativo es que el mensaje real

55 (1958) Shannon, Claude. E., Von Neumann's contributions to automata theory, Bulletin of the American Mathematical Society. Volume 64, Number 3, Part 2, pp.123-129.

56 (1990) Aspray, William, John von Neumann and the Origins of Modern Computing, MIT Press, Cambridge, Mass., pp.15-16.

57 Trabajó junto a Warren Weaver en los Laboratorios Bell. En 1949, ambos ampliaron la divulgación de la teoría de la información a través de un texto conjunto donde aumentaban el campo de aplicación de la teoría a todas las formas de comunicación. En el desarrollo del 'analizador diferencial' trabajó junto a Vannevar Bush. 
es seleccionado de un conjunto de posibles mensajes. El sistema debe estar diseñado así para funcionar en cada posible selección ${ }^{58}$

Las ecuaciones estadísticas en torno a este "conjunto de posibles" es la base de la teoría de la información que se integra a la cibernética de Wiener. Es sugestivo que el esquema de comunicación sobre el que Shannon desarrolla sus planteos denominándolo "sistema de comunicación" sea el mismo esquema general de componentes (emisor, receptor, fuente, canal, trasmisor...) que el presentado por Roman Jakobson (Escuela de Praga) en su "Linguistique et Poétique" de Ensayos de Lingüística General (1963). Este lingüista de fuerte identidad estructuralista, quien afirmó que pretendía buscar los componentes últimos de la lengua y construir un sistema similar a una tabla periódica de elementos químicos, es uno de los primeros lingüistas que se ocupa del lenguaje como instrumento de comunicación. Podría suponerse entonces que, a diferencia de Shannon, la semántica en la comunicación sí debiera tener alguna relevancia ${ }^{59}$. Pero, en ambos autores más allá de las particularidades de sus modelos y de sus antecedentes teóricos, el sistema de comunicación es un esquema funcional-instrumental análogo: el hablante (o emisor) empaqueta ideas (u objetos unívocos) usando las palabras (o vehículos) bajo un código y las envía (a lo largo de un conducto o canal) a un receptor que extrae las ideas (u objetos) de las palabras, decodificándolas. Coincidiendo en un esquema general que propone así una homología entre el ser humano y la máquina en un proceso de comunicación entendido como 'trasmisión'. Con la publicación posterior de Shannon, en 1949 y junto a Weaver, la teoría matemática de la comunicación se presenta ampliada a todas las formas de comunicación, este presupuesto de homología se tornará evidente y será fuente de influencia para los formalismos lingüísticos.

Herbert $\operatorname{Simon}^{60}$ en "La arquitectura de la complejidad" también da cuenta de la posibilidad de equiparar ámbitos aparentemente disímiles o incluso antagónicos a través de la matematización. Plantea que las primeras teorías desarrolladas en torno a la complejidad, por su abstracción o formalización, pueden tener relación con otros tipos de sistemas complejos que se observan

\footnotetext{
58 (1948) Shannon, Claude. E, "A mathematical theory of communication", Bell System Technical Journal, vol. 27, pp. 379-423 and pp. 623-656.

${ }^{59}$ En Francia, el movimiento estructuralista adoptó su propia variante del giro lingüístico en filosofía. A diferencia de la visión inglesa del lenguaje como habla y como comunicación intersubjetiva centrada en el significado, este movimiento se orientó al nivel de la lengua (Saussure), estudiando lo que consideraron las regularidades estructurales profundas que constituyen al lenguaje como sistema involuntario y arbitrario de signos diacríticos. Sus argumentos constituyeron un radical anti-intersubjetivismo que cuestionó la reducción del significado a la intención de los autores y desestimó el cambio y el proceso (o el desarrollo histórico) de un sistema de lenguaje, haciendo énfasis en las repeticiones de series de relaciones sincrónicas o en las trasformaciones que operaban dentro de estas últimas. A diferencia de estas perspectivas antihumanistas, que reprimieron la sociabilidad-historicidad, tanto Habermas como Gadamer introducen un momento histórico en sus teorías al destacar la dimensión retórica y pragmática del lenguaje como comunicación. La filosofía lingüística de franceses como Paul Ricouer y Maurice Merlau-Ponty, de modo excepcional, se acercan más a esta hermenéutica (alemana) que al estructuralismo francés. Ver (1990) Jay, Martin, "¿Debería la historia intelectual tomar un giro lingüístico? Reflexiones sobre el debate Habermas-Gadamer" en Socialismo fin-de-siècle, Nueva Visión, Buenos Aires, pp.27-49.

60 Herbert Simon, Premio Nobel de economía (1978) fue quien en el período 1952-1954, trabajando para la Rand corporation, concibió la idea de que la manera correcta de estudiar el proceso de "resolución de problemas" era simularlos con la ayuda de ordenadores. Un problema que se advierte en el modelar el comportamiento, si este no se efectúa bajo 'supuestos realistas', es que las predicciones tienen muy poca apelación práctica. Este aspecto "realista" fue entonces el rasgo priorizado por Simon.
} 
en las ciencias sociales, biológicas y físicas ${ }^{61}$. Ross Ashby, igualmente planteará este desafío permanente de la época por establecer un paralelismo entre las máquinas, el cerebro y las sociedades en el tratamiento de lo complejo $^{62}$. Pero, las contribuciones de Simon van a destacarse en el orden de los desarrollos de la "toma de decisiones" o, en la revolución de las formas de gestión de ese período.

La dirección de la complejidad de los desmesurados proyectos de la big science afectó al concepto de "racionalidad" y a la toma de "decisiones racionales" del que se deriva, encontrando nuevas alternativas de viabilidad a través de su transformación. Este proceso de investidura operacional/computacional de la idea de racionalidad humana, encuentra también en el organismo una imagen teóricamente representativa, pero en este caso es el organismo vivo (humano) el que es asimilado a la máquina. Así, en un reporte de Herbert Simon para la Rand Corporation". "A Behavorial model of rational choice" (1953) ${ }^{64}$, se propone "un modelo de comportamiento para la descripción de la elección racional de los organismos de capacidad computacional limitada", es decir del hombre. La "racionalidad limitada" es un modelo de racionalidad humana propuesta por Simon para modelizar en ciencias sociales (economía) intentando atenerse a lo que él entiende por una forma "más realista" de actuación de los agentes sociales, en el marco general de una "teoría de la elección racional" para la toma de decisiones. Una perspectiva teórico-instrumental-gerencial acorde a elecciones y planes en un mundo que es concebido por este economista bajo los problemas de la "complejidad organizada" 65 .

Apenas dos años antes del "Progress Report of the Air Defense Systems Engineering", se publica en la American Scientist el texto de Warren Weaver ${ }^{66}$, "Science and Complexity" (1948), allí el concepto de complejidad habría irrumpido públicamente en el vocabulario científico de un modo explícito, sistemático y consciente ${ }^{67}$. Cuando Weaver, en este texto pionero, deslinda y define los problemas de complejidad organizada, expresa: "todos ellos son problemas que implican tener que enfrentarse al mismo tiempo con un número importante de factores que están interrelacionados en un todo orgánico. Todos ellos son, en el sentido que aquí se considera, problemas de complejidad

\footnotetext{
${ }^{61}$ Enfatiza la descripción de la complejidad a través de jerarquías, en un mundo en que la complejidad evolucionaría a partir de la simplicidad. Las jerarquías poseerían como propiedad la cuasi descomponibilidad que simplificaría el comportamiento, la descripción y la comprensión del desarrollo -o reproducción- del sistema. (1979) Simon, Herbert, "La arquitectura de la complejidad" en Las ciencias de lo artificial, Ed. ATE, Barcelona, pp. 125-169

62 (1960) Ashby, Ross William, Introducción a la cibernética. Nueva Dimensión, Buenos Aires, pp. 1120

${ }^{63}$ A principios de la década de 1950, la Rand amplió su enfoque en sistemas mediante la inclusión de más economistas y científicos sociales que se incluirán en un total de 400 investigadores.

${ }^{64}$ Artículo disponible en la web: http://moreyaknow.com/wp-content/uploads/2011/02/P365.pdf.

65 Ver (1989) Simon, Herbert, Naturaleza y límites de la Razón Humana, FCE, Breviarios, México.

${ }^{66}$ Warren Weaver, creador de la expresión 'biología molecular' siendo director de la división de ciencias naturales del Instituto Rockefeller, durante la guerra reorientó sus intereses. Se mantuvo alejado de la revolución molecular que experimentó la biología y asumió plenamente los problemas derivados de su trabajo como dirigente de la sección de control de armas de la Oficina de Investigación y Desarrollo Científico durante la segunda guerra, interesándose en el estudio de los procesos técnicos de la comunicación (Shannon) y en las máquinas intencionales (Wiener).

${ }^{67}$ Rodriguez Zoya, P (en prensa) : La emergencia de los problemas de complejidad organizada en la historia de la ciencia contemporánea en Documentos de Trabajo, Grupo de Estudios Interdisciplinarios sobre Complejidad y Ciencias Sociales., Universidad de Buenos Aires, Buenos Aires, 2010.
} 
organizada". Weaver enfatiza (las cursivas son de él) y de este modo despeja los problemas de "complejidad organizada" de los de "complejidad desorganizada" a través de una imagen organicista. Si el carácter central de estos problemas es la organización, esta organización debe pensarse como un organismo vivo o como un "todo orgánico". En un párrafo posterior, y luego de ejemplificar este tipo de problemas, señala: "estos son también, obviamente, los problemas complejos, y ellos también implican el análisis de los sistemas que son totalidades orgánicas, con sus piezas en estrecha interrelación". Al hacer referencia a la conformación inaugural de "equipos mixtos" o equipos interdisciplinarios durante la Segunda Guerra, estrategia de vanguardia para el abordaje de los problemas complejos, Weaver exhibe como su fundamento el dictum organicista de las ciberciencias: 'el todo es más que la suma de las partes $^{68}$, textualmente: "se encontró, a pesar de las modernas tendencias hacia una fuerte especialización científica, que los miembros de grupos tan diversos pueden trabajar juntos y pueden formar una unidad que era mucho mayor que la mera suma de sus partes" ${ }^{69}$.

El régimen de poder convencional en sus diversos órdenes había quedado reestructurado bajo esta visión organicista. La inviabilidad de la acción directa o la gestión directa y jerarquizada de proyectos de enormes volúmenes y heterogéneas dimensiones (materiales, simbólicas, institucionales), las limitaciones de la economía de aplicación tradicional del saber, bajo la clásica división entre problema y especialidad para la resolución de problemas prácticos; o, las dificultades con las que se toparon los ingenieros de los Laboratorios del MIT y del Bell al diseñar sólo la conexión individual (por separado) de los componentes de un sistema fueron todas ellas limitaciones que empujaron a los regímenes tradicionales hacia su transformación bajo la idea de un "organismo" o un "todo orgánico" que posibilitó una nueva viabilidad. Ésta se hizo efectiva cuando los técnicos, científicos y gestores científicos y militares adoptaron otra visión, cuando se centraron en las interconexiones entre los "subsistemas" y "componentes" y dieron así especial interés a la "interfaz" entre las diversas partes. Resulta elocuente el hecho de que los constructores de sistemas incluyeran entidades dispares en un solo sistema: partes mecánicas, eléctricas y de organización. Así, partes de la organización total podían ser estructuras de gestión tales como un comando militar o entidades políticas (una oficina de gobierno). La organización general holística de los componentes en la gestión del proyecto, a menudo reflejaba especularmente las características sistémicas propias del diseño. Por ejemplo, una organización de gestión para presidir el desarrollo de un sistema de misiles intercontinentales podía ser dividida en divisiones que reflejaban las partes en que el misil se estaba diseñando. ${ }^{70}$

\footnotetext{
${ }^{68}$ Así por ejemplo, el compuesto $\mathrm{H} 20$ (y en esta perspectiva, el 'sistema agua') es irreductible en sus propiedades a las suma de las propiedades del hidrógeno y del oxígeno como sus componentes. Este dictum de inspiración aristotélica (para quien, a diferencia, sería una esenciación la que estructuralmente da unidad a los entes) es tematizado y explicitado por Ludwing von Bertalanffy : "Ias propiedades y naturaleza de los procesos de los niveles superiores no son explicables por la suma de las propiedades y naturaleza de los procesos de sus componentes considerados aisladamente", si bien serían deducibles (los niveles superiores) si se conociera el conjunto de los componentes y de las relaciones que los ligan. (1981) von Bertalanfly, Ludwing; Ashby, Ross y otros, Tendencias en la Teoría General de los Sistemas. Alianza, Madrid, p.33.

${ }^{69}$ (1948) Weaver, Warren, Science and Complexity, American Scientist 36, pp. 536-544. Las citas corresponden respectivamente a las pág. 538, 539, 540, 541.

${ }^{70}$ (2000) Hugues, Agatha y Hugues, Thomas, Op. Cit., p. 2
} 
Esta nueva factibilidad en el régimen de poder se expresa también en el contexto socio político donde el énfasis se ubica en la aptitud para la dirección de sistemas con un gran número de variables en interacción; o, en palabras de Weaver, en los problemas de "complejidad organizada". En contraste, los regímenes de poder convencionales modernos se habían desarrollado en contra de una visión orgánica del mundo, en la que la naturaleza, el hombre y el conocimiento formaban parte de un todo interrelacionado. La visión moderna o convencional, amparada en el paradigma filosófico que suele asociarse a Descartes, no tiene como fin último la compresión de las conexiones ocultas entre todas las cosas sino que, contrariamente, para ejercer dominio sobre la realidad esta debe ser descompuesta en fragmentos. ${ }^{71}$

La idea de causalidad moderna, en tanto la forma de pensar que ha dominado en la cultura occidental en más de los tres últimos siglos, también entra en cuestión. En la física clásica newtoniana se presupone que todos los eventos están causados por otros anteriores y que, por lo tanto, dicha causalidad es expresable en términos de leyes de la naturaleza o de forma determinista ${ }^{72}$. Al fijar la representación en un organismo biológico, la idea de una relación lineal directa y externa entre causa y efecto o, de otra forma, la noción heredera de la física moderna de una sucesión causal de eventos, muta en una concepción de interdependencia de la partes en una totalidad organizada. Ninguna parte, por sí misma, puede constituirse en la causa extrínseca del funcionamiento de otra parte, y a su vez, las partes no podrán ser entidades fijas, sino producto de las concurrencias de relaciones. Esta situación también manifiesta una oposición con el mecanicismo moderno en el hecho de que las totalidades sólo están constituidas por elementos con entidad propia, y a su vez, la totalidad sólo se remite al conjunto de sus elementos, nunca es más que su suma. La ciencia clásica habría intentado aislar los elementos de los ámbitos bajo su observación ('compuestos químicos y enzimas', 'sensaciones elementales' o 'individuos en libre competición' para la sociología liberal o economía clásica) en la creencia de que reuniéndolos de nuevo, conceptual o experimentalmente, emergería el todo (célula, mente o sociedad), pero en esta nueva visión científica son centralmente las interrelaciones entre elementos -y no sólo elloslos que permiten la emergencia de la totalidad. En contraste con el paradigma mecanicista lineal-causal de la ciencia clásica, se plantea así una nueva concepción del mundo como 'una gran organización'73

\footnotetext{
71 (2008) Castro Gómez, S: El lado oscuro de la época clásica. Filosofía, ilustración y colonialidad en el siglo XVIII En El color de la razón: racismo epistemológico y razón imperial (Walter Mignolo coord.), Ediciones del signo, Buenos Aires, p. 121. Para observar la relación entre el pensamiento cartesiano y el paradigma de la fragmentación o 'simplificación' por oposición al 'paradigma de la complejidad', ver (2001) Morin, Edgar, Introducción al pensamiento complejo. Barcelona, Gedisa, 2001, pp.29-31 y (1998) Morin, Edgar,El Método. IV. Las ideas. Madrid, Cátedra, pp.226-228. Para la relación entre pensamiento cartesiano y 'voluntad de poder' en los regímenes de poder tradicionales, ver (1973) Dussel, Enrique: Para una ética de la liberación latinoamericana, Siglo XXI, Buenos Aires, pp. 152 y 153. 72 Vale aclarar que hacia el interior de la física, en las primeras tres décadas del siglo XX, la física clásica sufrió importantes transformaciones mediante la aparición de la Teoría de la Relatividad (Eistein) que eliminó algunos de sus presupuestos básicos, la Mecánica Cuántica (Planck) que cuestionó la validez universal del principio de causalidad clásico y el Principio de incertidumbre (Heisenberg) que llevaron a la renuncia del principio de causalidad estricto.

73 (1981) Von Bertalanfly, L Ashby, R y otros, Op. Cit., p. 38 y p.46
} 
Esta perspectiva orgánica también alude a una nueva construcción de la realidad fenoménica. Distinguiéndose de las formas de conducta de acción lineal directa como las 'fuerzas' de la física clásica, las construcciones teóricas de base organicista sistémica permiten observar de qué manera las redes en interacción pueden dar origen a patrones estables y auto-perpetuadores de nuevas dinámicas, dando cuenta de una construcción fenoménica interactiva y emergente de un patrón radicalmente diferente de la que podría producir cualquier ente o conjunto de entes que se pensaran actuando de forma autónoma. Construcción del fenómeno científico que, a su vez, pone de relieve el carácter auto-generador de la nueva episteme operacional. Un ejemplo logrado en las ciencias sociales de la época son los trabajos de Gregory Bateson, que inspirados en la teoría de los tipos lógicos de Bertrand Russell, intentan dar cuenta de la esquizofrenia. Un modelo de interacción familiar comunicacional que da origen a patrones estables y auto-reproductores propios de las dinámicas de familias con pacientes esquizofrénicos. ${ }^{74}$ La ciencia social que este autor practica, del orden del comportamiento, ${ }^{75}$ presta mucha atención al desmontaje de ideas heurísticas vinculadas a la física clásica: fuerza, energía, materia, impacto, y a su vez, coloca el acento en otras tales como patrón, orden, diferencia, organización y comunicación. El tratamiento de estos asuntos, que para Bateson son de forma y no de sustancia y que también para él se habrían visto espectacularmente enriquecidos por la cibernética, la teoría de sistemas y la teoría de la información, es lo que lo convierte en uno de los primeros científicos sociales de la complejidad.

\section{Bateson: ciberciencias, organicismo y sociedad}

Un espíritu es un agregado de partes o componentes interactuantes. ¿Será capaz el sistema de tener alguna especie de preferencia estética?... ¿será capaz de tener conciencia? [G. Bateson]

La ideología organicista captura también el pensamiento social, renovándolo. Si para Bateson, en 1942, "es inconcebible que puedan coexistir uno junto al otro dos grupos diferentes en una comunidad, sin que se de algún tipo de pertinencia recíproca entre las características especiales de un grupo y las del otro", es porque "tal falta de pertinencia sería contraria al postulado de que una comunidad es una unidad organizada". Así, Bateson acuerda en una ideología organicista:

Primero, el individuo, sea desde el punto de vista fisiológico o del psicológico, es una entidad organizada única, de tal forma que todas sus 'partes' o 'aspectos' son mutuamente modificables e interactúan mutuamente, y segundo,

\footnotetext{
74 (1998) Bateson, Gregory, Pasos hacia una ecología de la mente. Una aproximación revolucionaria a la autocomprensión del hombre, Lohlé-Lumen, Buenos Aires, pp. 331-399

${ }^{75}$ Esta visión del comportamiento mantiene distinciones con el conductismo (behavioristics) típico de las ciencias sociales de la época, donde el hombre es considerado un organismo que configura una misma adaptación ante situaciones idénticas. O, de otra forma, donde el comportamiento humano depende de factores comunes a todas las formas de acción humana; una ciencia de la conducta que excluye a la libertad y a la lógica del deseo cuando define al hombre y a la sociedad como mero fenómeno natural.
} 
que una comunidad esta organizada de la misma manera en lo que a esto respecta $^{76}$

Estos, que serán postulados de análisis de los sistemas complejos, son también postulados del análisis de la sociedad en tanto "organismo vivo". En este sentido, esta antropología se presentó enfrentada a la escuela francesa de sociología. Y, como señala Winkin, si bien Bourdieu habría hecho esfuerzos para introducir esta perspectiva en 1966 con la publicación de Naven (1936), ésta no tuvo la influencia esperada ${ }^{77}$. Aunque hoy podríamos decir que el concepto de habitus ${ }^{78}$ tan distintivo de la teoría sociológica de Bourdieu, evoca un aire de familia con la "formación de hábitos a-perceptivos" de Bateson, quien a diferencia del estructuralismo francés de la época, concibe una "regularidad" del lado del Sujeto ${ }^{79}$ (inconsciente y socialmente introyectada por el aprendizaje) que permite dar cuenta de las diferencias sin agotarlas en una referencia a las tradiciones históricas o a las circunstancias en las que viven los sujetos $^{80}$. Más precisamente, me refiero al habitus como ese sistema de disposiciones que funcionaría como esquemas de clasificación que orientan las valoraciones, percepciones y acciones de los sujetos; es decir a un principio generador y estructurador de prácticas y representaciones culturales: los "hábitos" en Bateson. Disposiciones que para este último, se actualizan en una red de interacciones que es la cultura.

También hoy podría sostenerse que metodológicamente, en esta nueva visión sistémica de construcción del objeto en ciencias sociales, de modo análogo a algunos aspectos de la práctica que presenta Bourdieu, se evita "correr el riesgo de buscar ( $y$ 'encontrar') en el fragmento estudiado mecanismos o principios que son en realidad externos a él, y que se deben a sus relaciones con otros objetos" ${ }^{\prime 1}$, en tanto el objeto abstraído no es sólo construido sino que además es siempre parte de un espacio (o "sistema") social mayor. Eludiendo así los riesgos de una substantivación y consecuente 'esencialización' de determinados atributos de la realidad social cuando esta es recortada y objetivada por la investigación social.

En el sentido precedente, el trayecto intelectual de Bateson parece sugerir que su inicial trabajo en el campo antropológico (como aquel vinculado a los conceptos de 'cismogénesis'/ 'zigogénesis') se aviene como pretexto para reflexionar sobre procesos y mecanismos de las relaciones e interacciones

\footnotetext{
76 (1998) Bateson, Gregory, "Moral y carácter nacional" En Ibid, pp. 115-132. Las citas corresponden a las págs. 118 y 117 respectivamente [las cursivas son del autor]

77 (1991) Winkin, Yves (coord), Bateson. Primer inventario de una herencia, Nueva Visón, Buenos Aires, p. 133.

${ }^{78}$ (1999) Bourdieu, Pierre, Meditaciones pascalianas, Angrama, Barcelona, pp.183-185. Dada la centralidad del concepto éste esta presente en numerosos escritos del autor.

79 Esa "regularidad" es entendida por Bateson en un Sujeto que siempre es un sistema complejo de relaciones y no un ente individual (un 'individuo social' dirá Bourdieu).

${ }^{80}$ La sociología francesa ha actualizado de diversas formas la tesis de Durkeim por la cual existe una radical autonomía de las tendencias sociales frente a las tendencias individuales-psicológicas, y donde el hecho social es justamente aquello que no puede ser absorbido en absoluto por el individuo; en sus antípodas, la antropología cultural de EEUU parte de esas tendencias individuales-psicológicas para comprender la vida en sociedad. Para un análisis comparativo ver Bensa, Alban, "Individuo, estructura, inmanencia. Gregory Bateson y la Escuela francesa de Sociología" En Winkin, Yves (1991) Op. Cit. pp.135-151.

${ }^{81}$ (2005) Bourdieu, Pierre, "La práctica de la sociología reflexiva" en Bourdieu, P y Wacquant, L, Una invitación a la sociología reflexiva, Siglo XXI, Buenos Aires, p. 287
} 
sociales en general, en el horizonte de un "sistema social mayor". Los estudios de la época están enmarcados en una escisión entre la teoría y la metodología, en donde el corpus empírico se presenta bajo la potestad incondicionada de la experiencia. Esta última da validez al conocimiento del "funcionamiento de la estructura global" de una etnia, grupo o sociedad 'porque se ha estado alli' en acuerdo con reglas metodológicas del trabajo de campo; por acuerdo con las reglas del método de los procedimientos lógicomatemáticos estadísticos en sociología; o, por la seguridad de que los documentos 'revelarán los hechos' en el caso de la investigación histórica. En contraste, los hechos científicos en Bateson se presentan como referencias de base para especular, y en esta tensión disruptiva del carácter perentorio de la "prueba empírica" propia del método experimental, anticipa la conciencia del carácter constructivo del objeto de investigación en ciencias sociales. Premisa que desarrollará Bourdieu en su obra en coautoría con Passeron "El oficio de sociólogo" (1966) en abierta disconformidad con lo que calificará como "el fetichismo de la data' o como el "paradigma positivista de esa época", en un intento por construir un modelo alternativo de sociología empírica que se halle fundada teóricamente. ${ }^{82}$. Así, las que podrían considerarse desviaciones metodológico- disciplinarias de Bateson para la ciencia social estadounidense de las décadas del 30 y del 40, pueden leerse ulteriormente como sus mejores aciertos. Cuando hace este ejercicio en torno al alcoholismo ${ }^{83}$, en este caso, el material empírico le sirve explícitamente para asentar su reflexión epistemológica. Una reflexión que al integrar la epistemología con la ontología en la vida cotidiana, le permite expandir el sentido tradicional filosófico de la epistemología a los supuestos de todas las formas del saber, una connotación de la idea tradicional que hoy se halla instituida.

Por ello, no es casual que a pesar de tener una fuerte formación científica natural, el empirismo como pensamiento científico ingenuo sea elucidado por este autor ${ }^{84}$. Uno de sus postulados básicos es que la ciencia nunca prueba nada: "la ciencia a veces mejora las hipótesis y otras veces las refuta, pero probarlas es otra cuestión, y esto tal vez no se produzca jamás salvo en el reino de la tautología totalmente abstracta" ${ }^{\prime 25}$, nunca en la biósfera (podría fielmente agregarse). Este postulado esta alejado de un interés racionalista por delimitar deontológicamente qué es o cómo progresa el conocimiento científico tal y como, por ejemplo, el racionalismo crítico de las conjeturas y refutaciones de Popper nos proponen; por el contrario, en Bateson la 'metafísica' y la 'ciencia' no están escindidas. Sus concepciones "eran un alegato en defensa del espíritu inmanente, es decir del proceso mental que se produce dentro de estructuras físicas de apropiada complejidad". El fenómeno mental alude a los procesos de reacciones a las diferencias, a la comunicación y a la organización en estructuras materiales diversas (un organismo vivo, una comunidad tribal, una sociedad o un ecosistema). Una visión en franca oposición con el dualismo cartesiano moderno que expulsa el espíritu de la materia, convirtiéndolo en "transcendente", y despoja a la materia de su

\footnotetext{
82 (2000) Bourdieu, Pierre, "Conversación: el oficio de sociólogo" en Capital cultural, escuela y espacio social. Siglo XXI, México, pp.41-64.

83 (1998) Bateson, Gregory, Op. Cit., pp. 345-367

84 Sobre la limitación del empirismo y la inferencia inductiva para la producción de conocimiento fundamental en ciencias ver Ibid, pp.19-20.

${ }^{85}$ (1997) Bateson, Gregory, Espíritu y Naturaleza, Amorrortu, Buenos Aires, p. 37.
} 
carácter "mental". Con la consecuente división del trabajo entre la 'ciencia' y la 'metafísica' que hace que el conocimiento científico "escinda todo en pedazos" y que "un teólogo o filósofo tenga derecho a hablar del espíritu como algo totalmente separado de la materia" $"$.

Bateson dirá como respuesta a la pregunta acerca de la naturaleza del conocimiento, que él cree que su propio conocimiento "es una pequeña parte de un conocimiento integral más amplio que entrama toda la biósfera" ${ }^{\prime 7}$. Una verdadera weltanschauung organicista que condensa el plano intelectual, moral y material. Cosmovisión que entra en ruptura con la modernidad al acoplar al sujeto y objeto de conocimiento en una referencia recíproca interminable. El sujeto nunca es definitivamente exterior al objeto y el objeto nunca es pasivo, siempre vuelve sobre el sujeto, en tanto las características mentales de la biósfera como conocimiento integral, son inmanentes no a alguna de las partes (como a un sujeto que piensa) sino a la biósfera en su totalidad. Así, Bateson argumenta que "la unidad de supervivencia, tanto en la ética como en la evolución, no es el organismo ni la especie sino el sistema máximo dentro del cual vive el ser animado, si este ser destruye a su ambiente, se destruye a sí mismo"88. En el mismo pensamiento holista queda subvertida la relación cognoscitiva convencional entre sujeto y objeto de conocimiento y la idea de control o dominio unilateral tradicional de la modernidad.

La reflexión de este autor sobre la política se efectúa en los mismos términos que la descripción y análisis de una comunidad, una familia o la sociedad. Un marco conceptual explicativo de corte cibernético basado en el comportamiento de los sujetos. Su perspectiva brinda el sugerente aporte de visualizar al 'poder' como característica de toda relación humana y concluir que todos siempre estaríamos inmersos en la esfera de la "política", en tanto para Bateson el concepto de sociedad se define en y desde las relaciones e interacciones sociales de los sujetos ${ }^{89}$. En su escaso tratamiento de temas típicamente políticos, Bateson afirma cuestiones tales como que los peores desastres del siglo XX -desde el tratado de Versalles a Hiroshima- son consecuencias de una conducta basada en una "patología epistemológica" que ha incentivado la "arrogancia humana"90. Así, por ejemplo, un problema socio político de la época puede ser reformulado en el orden del comportamiento de los sujetos y en su carácter sistémico [en la siguiente cita ya intervienen las invenciones cibernéticas, en el contexto de la guerra fría]:

\footnotetext{
${ }^{86}$ (1991) Bateson, Mary Catherine, "Como nació Angels fear" En Op. Cit., 23-36. Las citas corresponden a la pág. 25. En relación al dualismo cartesiano, el fisicalismo y el cuantitativismo ver (1997) Bateson, Op. Cit., pp.231-232.

87 Ibid, p.102

88 (1998) Bateson, Gregory, Op. Cit., p. 362

89 Este sentido que enfatiza las acciones recíprocas, el carácter procesual de lo social y las relaciones sociales, distanciándose de visiones substantivadas de categorización, mantiene afinidad con la sociología de Georg Simmel. Ver en particular (2002) Simmel, Georg, Cuestiones fundamentales de sociología, Gedisa, Barcelona, pp. 32-33 y 78. Si bien esta visión sistémica parece más bien distante de la fenomenología, hermenéutica o filosofía de la vida presentes en Simmel, mantiene un distanciamiento común con la escuela durkheimiana francesa al atribuir un papel central al Sujeto y a las interacciones entre los individuos como base de los procesos sociales y culturales (en esta visión sistémica, por la influencia del individualismo liberal y el conductismo en la antropología y sociología estadounidense).

90 Ibid., pp. 501-509
} 
Los departamentos de Estado de varias naciones emplean actualmente la teoría de los juegos, respaldada por computadoras, como método para decidir su política internacional (...) Entonces piden a la computadora que compute cuál debe ser nuestra próxima jugada para reducir al mínimo nuestras posibilidades de perder en el juego (...) Pero si usted hace lo que la computadora aconseja esta aseverando que apoya las reglas del juego que usted dictó a la computadora (...) Indudablemente, las naciones que están en el otro bando poseen también computadoras y están jugando juegos semejantes y reafirmando las reglas que dictan a sus computadoras. El resultado es un sistema en el cual las reglas de la interacción internacional se tornan cada vez más rígidas. Mi opinión, es que lo que anda mal en el campo internacional es que las reglas necesitan ser cambiadas ${ }^{91}$

Este devenir metadiscursivo sistémico de Bateson es similar al tratamiento de cualquier otro objeto, su pensamiento político no se distingue de su pensamiento científico. En él se presenta una permanente práctica de traducción que da cuenta de las nuevas ciencias y tecnologías como revolución epistémica. Desarrolla categorías como "información", "circuito interactuante", "retroalimentación", "flexibilidad del sistema", "interacción", "diferencia que hace una diferencia", "patrones", "ecología de las ideas", "regulador", "flexibilidad del sistema", "interruptor", "información del sistema", "ecosistemas autocorrectivos", "características analógicas y digitales", "codificación" "metamensajes", "metarelaciones", "deuteroaprendizaje", "tautología ecológica" y otras. Efectúa referencias recurrentes a una explicación 'negativa' (distintiva de la cibernética) o a nuevas formas cognitivas a través de la idea de un "funcionamiento de un circuito integral", enfatizando la atención en la "relación" por sobre los términos relacionados. Ideas que enlazadas a postulados provenientes de la lógica, teorías biológicas y evolucionistas, y a conceptos de las ciencias sociales le permiten re-describir y pensar en términos de comportamiento sistémico cuestiones muy diversas, llevando así el pensamiento complejo hacia los problemas sociales, culturales, éticos y de civilización. En Bateson, se observa así un ejercicio de comprensión de los fenómenos sociales bajo los principios de las ciberciencias pero en una analítica de la complejidad sin reducción al lenguaje de la calculabilidad (basada en la aritmética operacional, la axiomatización y formalización) esencial para la emergencia de estas nuevas ciencias tecnológicas. Dicho de otra forma, su metódica de pensamiento complejo no es reabsorbida integralmente por las reglas de la lógica simbólica (o de la cantidad matemática), y también en este sentido, puede considerarse uno de los primeros científicos sociales de la complejidad. Pero además, en él la complejidad no se advierte como un ejercicio de crítica puramente intelectual sin repercusión en la existencia personal o vital, por ello podría sugerirse igualmente que bosqueja una primera "ontología" de la complejidad.

\section{Conclusiones, otra posible vía exploratoria}

Bajo una metanarrativa de reconstrucción de las "nuevas ciencias y tecnologías" el proceso histórico de emergencia de la ciberciencias y de la complejidad tiende a desaparecer, en tanto la historia de estas nuevas

91 Ibid, p. 508 [las cursivas son mías] 
disciplinas se presenta asimilada al surgimiento de la tecnología como nuevo fenómeno sociológico. Si por el contrario, se efectúa una reconstrucción del surgimiento de las teorías de la complejidad expulsando su contexto de emergencia, se corre el riesgo de permanecer en un 'centrismo' científico. Una emergencia que sólo se entendería como resultado de las propias reglas internas del trabajo científico, en donde la producción, circulación y validación social de estas nuevas teorías quedarían reducidas a la mera aptitud de científicos individuales o grupos interdisciplinarios inmersos en una práctica guiada por valores e intereses universales, 0 por trayectorias, tradiciones $e$ intereses propios a la institucionalidad de la ciencia ${ }^{92}$. Es decir, una producción científica socialmente aséptica que luego es 'impuesta', 'derramada' o 'extendida' a través de diversos mecanismos políticos a la sociedad. De hecho, los cibercientíficos más representativos pueden ser ubicados en el marco de una comunidad científica (en el sentido khuniano) o bajo un encuadre sociológico institucional o neo-institucional de la práctica científica, pero estos enfoques no explicarían su simultánea vinculación a las fuerzas armadas, el estado, o a importantes corporaciones y fundaciones durante todo el período de guerra y posguerra. Destacándose que son precisamente estas otras vinculaciones sociales, políticas y económicas las que generalmente influyen reorientando los intereses 0 inquietudes científicas sobre los problemas específicos del orden de la complejidad y que, a futuro, pre configurarán nuevos programas de investigación como el de la inteligencia artificial y el de las ciencias cognitivas, produciendo además innumerables influencias en otras líneas de investigación.

Al presentar el enlace entre la emergencia de las ciberciencias con una sociedad particular, también se hace posible visualizar como credo de época una ideología organicista, imaginario colectivo de científicos y técnicos que da cuenta de una afectación en principios cognitivos, sociales y políticos de los dispositivos convencionales de la modernidad. $Y$ en este sentido, esta matriz epistémica organicista en la que se lleva adelante la práctica científica más transformadora para la sociedad de la época, es también la que permitiría dar cuenta de una nueva viabilidad en los regímenes del poder- del- saber. Una inflexión en la sociedad estadounidense en donde la "complejidad organizada" se instituye como problema político y científico en una nueva alianza. Ligadura entre el poder y la ciencia que encuentra su correspondencia en la nueva alianza sociocultural entre las ciberciencias y la sociedad a través de innovadoras formas de administración de las estructuras sociales y tecnológicas entendidas como 'circuitos funcionales de sistemas' donde

\footnotetext{
92 Una vía exploratoria, en una variante de este segundo tipo, se encuentra formulada por Pablo Jensen, éste propone para el estudio de la historia del campo emergente de los sistemas complejos un análisis de redes, característico de los estudios de la ciencia. Este planteamiento, en particular, enfatiza el aspecto metodológico de modelización para la exploración histórica, partiendo de la bibliografía adjunta a los temas de sistemas complejos para la elaboración de datos. Propone identificar las principales etapas históricas de la aparición del área de estudios en complejidad utilizando el análisis de redes heterogéneas (Andrei Mogoutov). De modo esquemático, un primer paso sería identificar a algunos autores (p.e. Von Neuman) o laboratorios (p.e. Santa Fe) como palabras claves que sirven para construir una primera "base de datos". Una vez que los pocos miles de artículos relacionados con las referidas palabras claves son identificados, se efectuaría el análisis de la red resultante. A continuación, los resultados se discuten con los actores o informantes clave en el área. (Ver sitio web http://perso.ens-lyon.fr/pablo.jensen/). Esta perspectiva exploratoria de la historia, si bien posee un encuadre metodológico- instrumental preciso (basado en la modelización de los sistemas sociales) presupone la emergencia de la "complejidad" (y de modo específico su campo de estudio) en escisión con procesos sociales, políticos, económicos y culturales de una sociedad particular.
} 
inauguralmente se entrelazan elementos heterogéneos, materiales y simbólicos bajo un mismo estándar; y en el futuro mediato, perturbando estructuras del capitalismo clásico a raíz de los cambios producidos por el uso de estas nuevas ciencias y tecnologías en rápida expansión.

Así, puede seguirse que la idea de "complejidad" surge en un entramado donde el régimen interno de producción científica, la situación de guerra y posguerra y la sociedad estadounidense son actores insoslayables, interactuantes y condicionantes de su misma aparición. No existiría un punto neutro en el que "la complejidad" se constituiría como concepto por fuera o más allá de la ideología. El discurso de las ciberciencias estaría tan socialmente determinado en su producción de sentido como otros, aunque su particular determinación social de producción se efectúe bajo los mecanismos propios del discurso científico. Por ello, en esta propuesta de exploración histórica no sería adecuado aislar autores como si sus teorías y discursos hubieran sido elaborados en condiciones de preservación sociocultural y de época.

El énfasis que todas las producciones teóricas vinculadas a la complejidad dan al comportamiento, la conducta o a la operación desde las más diversas disciplinas, permite deducir esta impregnación cultural e histórica. Así, la interrogación general y las respuestas a los problemas científicos relacionados con las nuevas ciencias e incluso su misma 'construcción problemática', no se orienta al ¿qué es y cómo se compone? sino al ¿qué hace y cómo? en la marca de la ciencia anglosajona de ese período. $Y$ en esta tradición, no es casual que este carácter funcional y conductista sea la idea general referida a un "sistema complejo". Esta noción se atiene sólo a los modos de comportamiento y se libera de su posible carácter material o sustancial (social, biológico, organizacional o físico). El interrogante cibernético es ¿cuáles son todos sus modos de comportamiento posibles? Y luego, ¿por qué este caso particular se adecua al comportamiento ordinario? o ¿cómo se adecúa a la restricción particular ordinaria?; da cuenta así de hasta qué punto la conducta resulta relevante al centrar la atención científica en las restricciones por la cual ésta esta sujeta o gobernada o, en cómo es posible replicarla en su capacidad de intencionalidad, auto-reproducción y adaptación a partir de analogías con la conducta del organismo biológico.

De modo general, la "mecanización de la imagen del mundo" significó el pasaje de la metáfora del mundo como organismo (un cuerpo o un animal) a la del mundo como máquina mecánica en la revolución científica del siglo XVII, asociada ésta con la emergencia del paradigma moderno. Si bien habría que examinar cuidadosamente las limitaciones y posibilidades de maleabilidad social ante esta nueva imagen retrospectiva de un "todo orgánico" más allá de lo atinente al surgimiento de las ciberciencias, lo socialmente transformador es que la máquina mecánica puede ser re concebida como un organismo vivo y el organismo vivo como máquina para la creación de un nuevo cosmos social maquínico: nuevas formaciones sociales del tipo inaugural del de un "Sistema de Defensa Antiaéreo", hoy naturalizadas en las concepciones mismas de gestión de un servicio público; nuevos artefactos como el "computador electrónico" que también ha cristalizado nuevas formas de sociabilidad cotidiana; rupturas en las representaciones sobre nuestra forma de 
comunicarnos y conocer, ya sea "trasmitiendo" mensajes o ideas a través de un proceso "transductor" o bien insertos en una "red informacional", en un espacio/tiempo concebido como un circuito de componentes interactuantes virtual o tridimensional.

Este nuevo universo maquínico social, que supone un nuevo proceso de racionalización de la vida a través de una recreación de la hegemonía de los medios técnicos, se corresponde con un nuevo paradigma cognoscitivo que reemplaza la idea moderna de objeto de conocimiento por una posmoderna de sistema, donde lo susceptible de ser objetivado científicamente está dotado de organización y el sujeto cognoscente por excelencia es 'pro-activo' y 'organizado'. Racionalización sistémica que, paradójicamente y a un mismo tiempo, reactualiza y desborda la idea weberiana de modernidad científica como construcción, afirmación y dominio de la racionalidad científicotecnológica-gerencial, un saber que presupone que todas las cosas pueden ser controladas a través del cálculo en un actuar racional de acuerdo con fines. Y que, a su vez, confirma su posmodernidad al desdibujar la representación cuasi antinómica moderna weberiana de 'el científico' y 'el político' en tanto el "especialista sin espíritu" se transforma en el "líder carismático".93

Así, la metáfora retrospectiva del mundo como organismo habría funcionado como un imaginario científico que es germen y no modelo omnisciente de la transformación e inflexión en la sociedad estadounidense. En esa etapa de giro, 'lo complejo' surge comprendido bajo este canon orgánico en un singular sesgo evolucionista, donde las transformaciones de la vida a lo largo del tiempo pueden ser determinadas por mecanismos precisos susceptibles de cálculo. De un modo consecuente, la sociedad será concebida analíticamente como una 'gran entidad organizada' o como 'una gran máquina orgánica' bajo un espectro sociopolítico bélico-controlador.

Finalmente, podría recapitularse y concluirse que la noción de complejidad y las condiciones socio-históricas (políticas, económicas y culturales) de la sociedad en la que afloró son inmanentes. En tal sentido, una empresa de reconstrucción que intentará abstraer el concepto científico de complejidad y sus teorías de una sociedad particular donde ha emergido, estaría transformando en transcendente a alguna de las dos, ejerciendo un constreñimiento explicativo frente a una relación de reciprocidad que las ciencias sociales y humanas de hoy parecen no habilitar.

\footnotetext{
93 Me refiero a la tesis de libertad valorativa de las ciencias sociales sostenida por Weber, a la diferencia radical que establece entre el conocimiento objetivo o ciencia de los hechos universalmente válidos y la valoración subjetiva o toma de posición -política, ética, social- del investigador social. Ver en particular (2009) Weber, Max, "La ciencia como profesión" En El político y el científico, Prometeo, Buenos Aires, p.30. Ver (2007) Löwith, Karl, "La posición de Max Weber frente a la ciencia" en Max Weber y Karl Marx, Gedisa, Barcelona, p. 158 y p. 162.
} 